\title{
Adsorption of dimethyl ether (DME) on zeolite molecular sieves
}

\author{
Jai B. Lad and Yassir T. Makkawi*
}

Chemical Engineering and Applied Chemistry, School of Engineering and Applied Science, Aston University, Birmingham B4 7ET, United Kingdom

\begin{abstract}
In recent years there has been growing interest in the use of dimethyl ether (DME) as an alternative fuel. In this study, the adsorption of DME on molecular sieves $4 \AA$ (Mol4A) and $5 \AA$ (Mol5A) has been experimentally investigated using the volumetric adsorption method. Data on the adsorption isotherms, heats of adsorption, and adsorption kinetic have been obtained and used to draw conclusions and compare the performance of the two adsorpents. Within the conditions considered, the adsorption capacity of Mol5A was found to be around eight times higher than the capacity of Mol4A. Low temperature adsorption and thermal pre-treatment of the adsorbents in vacuum were observed to be favourable for increased adsorption capacity. The adsorption isotherms for both adsoprbent were fitted to the Freundlich model and the corresponding model parameters are proposed. The adsoprtion kinetic analysis suggest that the DME adsorption on Mol5A is controlled by intracrystalline diffusion resistance, while on Mol4A it is mainly controlled by surface layering resistance with the diffusion only taking place at the start of adsorption and for a very limited short time. The heats of adsorption were calculated by a calorimetric method based on direct temperature measurements inside the adsorption cell. Isosteric heats, calculated by the thermodynamic approach (Clasius-Clapeyron equation), have consistently shown lower values. The maximum heat of adsorption was found to be $25.9 \mathrm{~kJ} \mathrm{~mol}^{-1}$ and $20.1 \mathrm{~kJ} \mathrm{~mol}^{-1}$ on Mol4A and Mol5A, respectively; thus indicating a physisorption type of interactions.
\end{abstract}

Key words: adsorption; DME; molecular sieves; isotherm; heat of adsorption; adsorption kinetics

\footnotetext{
* Corresponding author: +44 (0)121 204 3398; e-mail: y.makkawi@aston.ac.uk
} 


\section{Introduction}

Gas separation and purification by adsorption has been widely studied in the past for broad range of applications involving various types of adsorbate/adsorbent. Methane, ethane, butane, propane, aromatics and air pollutants are examples of gases that have received much attention for adsorption due to their relevance to industrial applications [1.2]. This study is focused on the adsorption of dimethyl ether (DME), also known as methoxymethane $\left(\mathrm{CH}_{3} \mathrm{OCH}_{3}\right)$, on zeolite molecular sieves. DME is a relatively unexplored gas in adsorption applications. It has numerous advantages including, but not limited to, high hydrogen to carbon ratio, high energy density, non-corrosive, noncarcinogenic, non-toxic nature and no carbon-carbon bonds. Consequently, it can be easily handled, stored, transported and burned with limited negative environmental impacts. These factors make DME an attractive option for use as an alternative fuel for internal combustion engines. Currently, the most common method for the commercial production of DME is by catalytic dehydration of methanol [3,4]. DME is also produced as a by-product of methanol synthesis [5] and from biomass driven syngas [6]. On the one hand, DME has a large potential for future applications but since it is environmentally benign [7] and only synthesised in small quantities developments of methods that allow for purification or selective separation of DME are required.

Synthesized zeolites, collectively referred to as molecular sieves are of crystalline lattice structure and highly porous giving rise to high adsorptive qualities at a high chemical and thermal stability. Zeolites can separate mixtures via adsorption, diffusion differences and molecular sieving effects. The kinetic selectivity and molecular sieve properties are determined by the nominal diameter of the windows in the channel structure. Borgmann et al. [8] reported that small molecular sieves in the range of 4.3-5.0 $\AA$ are more favourable for the adsorption of DME.

A review of the literature reveals that there is only handful of studies on DME adsorption. The most five relevant studies [9-13] are summarized in Table 1. Robinson and Ross [9] and Anderson and Rochester [10] both reported experimental investigations of DME adsorption on silica gel. In and both studies it was noted that DME adsorbs on silica gel as a result of hydrogen bonding. Robinson and Ross [9] study was carried out at the boiling point of DME (much lower temperature compared to this study) by measurements of the adsorption/desorption isotherms and isothermal calorimetric heats of adsorption. The heat of adsorption was found to be in the range of $20-16 \mathrm{kcal} \mathrm{mol}^{-1}$. It was also shown that the thermal pre-treatment of the gels at lower temperatures resulted in increased sorption, but when impregnated with aluminium the adsorption favoured gels treated at higher temperatures. Anderson and Rochester [10] reported that for weakly adsorbed DME only one methoxy group in each molecule was bonded to a silanol group. The stronger mode of adsorption involved both methoxy groups in each DME molecule bonded to the adsorbent and therefore formed a dominant 
mode of adsorption at low coverage. However, it was also cited that due to the strong hydrogen bonds, subsequent desorption showed evidence of resistance even after prolonged vacuum. Reyes et al. [14] investigated pressure swing adsorption (PSA) and temperature swing adsorption (TSA) separation of DME from a hydrocarbon gas mixture using eight membered ring zeolites. It was reported that these zeolites have window sizes comparable to the molecular dimensions of DME. The upper adsorption temperature limit for PSA was recommended to be in the range 323-523 K for the pressure range of 5-200 $\mathrm{kPa}$. In the TSA, the recommended operating temperature was in the range of $323-423 \mathrm{~K}$ for the pressure range of $20-200 \mathrm{kPa}$. The upper temperature limit was to avoid unwanted side reactions and polymerization during desorption stage.

The literature review suggests that the adsorption of DME is achievable on both silica gel and molecular sieves, with the latter appearing more attractive due to its high selectivity. Nevertheless, there is still a gap of knowledge due to limited published data and lack of details in terms of adsorption isotherms, kinetics and heat of adsorption, particularly with molecular sieves. Therefore, the main goal of this study was to investigate the DME adsorption and the underlying bonding mechanisms on two different types of zeolites adsorbents and provide quantitative data that may help in developing processes for its selective separation. For this purpose, volumetric adsorption experiments were carried out within the pressure range of $0-4.0$ atm on Type- $A$ zeolites $4 \AA$ (Mol4A) and $5 \AA$ (Mol5A). Both selected adsorbents have a pore size distribution close to the molecular size of DME. Details on the adsorbents surface area, morphology, chemical composition, thermal stability and moisture contents were determined using various analytical tools. In order to understand the gas binding behaviour the heat of adsorption was calculated using a new calorimetric method and the results were compared with the widely used isosteric heat of adsorption obtained from the ClasiusClapeyron equation $[15,16]$.

\section{Experimental}

\subsection{Apparatus}

The adsorption analysis was carried out using the volumetric adsorption method. Fig. 1 shows the simplified experimental set-up used. The set-up was constructed in-house using Swagelok fixtures and fittings and mainly consists of five parts: (i) gas flow meter (ii) manifold region (iii) digital pressure gauge (iv) adsorption cell [AC] (v) vacuum pump [VP]. The AC used was a custom-built vertical stainless steel cell commercially known as a FlowCat reactor (6 mm ID x $151 \mathrm{~mm}$ ) supplied by HEL Group Ltd, UK. This was equipped with a very fine mesh $(50 \mu)$ at the bottom to support the adsorbent and a top removal cover with an opening to allow loading and off-loading of the adsorbent solid. A pre-calibrated flow meter (type: Variable-Area; Brooks Instruments, UK) was positioned 
prior to the manifold region to control and measure the gas supplied to the manifold. A high precision digital pressure gauge (model: DPG409; Omega Engineering, UK) in the range of 0-500 psiA (max of $34.02 \mathrm{~atm})$ and gauge error $\pm 0.02 \mathrm{psiA}\left( \pm 1.36 \times 10^{-3} \mathrm{~atm}\right)$ was positioned in the manifold line. The pressure gauge was connected to a data acquisition module (type: OM-USB1208FS) to record the pressure every one second. Two $K$-type thermocouples were connected to a data logger (model: HH806AWE; Omega Engineering, UK) to record the temperature in the manifold and inside the adsorption cell every one second. A heating tape installed around the adsorption cell and connected to a power controller was used for heat supply during higher temperatures tests. A hybrid vacuum pump, combination of a two-stage rotary vane pump and a two-stage chemistry diaphragm pump for optimized corrosion resistance (model: Vacuubrand RC6 Chemistry Hybrid) was used to create an ultimate vacuum of $2 \times 10^{-6}$ atm prior to carrying out the experiments. The whole set-up was mounted inside a purpose built metal framework as shown in Fig. 2. All experiments were conducted inside a fume-cupboard due to the nature of the adsorbate gas.

\subsection{Materials}

The two different types of synthetic zeolites, namely types Mol4A ( $4 \AA$ ) and Mol5A (5 $⿱$ ) ), were selected for this study due to their pore size distributions being close to the molecular dimension of DME. Walker et al. [17] reported the average free aperture pores sizes of Mol4A and Mol5A to be $3.5 \AA$ and $4.2 \AA$ respectively, whereas Triebe et al. [1] reports these to be $3.8 \AA$ and $4.4 \AA$. respectively. It is important to recognise that these are the mean aperture pore sizes and the actual pore size distribution may slightly vary depending on the manufacturing procedure. Further physical and chemical properties of the zeolites used, as provided by the supplier, are given in Table 2 . The detailed analyses of the adsorbent surface morphology and chemical composition are given in the results sections. Both adsorbents were subjected to an ultimate vacuum and/or thermal pre-treatment to investigate the effect of such pre-treatment on the adsorption capacity, as discussed in the results section.

The adsorbate gas of DME $\left(\mathrm{CH}_{3} \mathrm{OCH}_{3}\right)$ was of $\geq 99.0 \%$ purity and supplied to the adsorption rig from a $400 \mathrm{~g}$ pressurised cylinder. The DME chemical structure (see Fig. 3) shows symmetry with two equivalent CO bonds of $1.411 \AA$ and two sets of C-H bonds (1.090 $\AA$ in-plane and $1.099 \AA$ out-ofplane) [18]. Further physical and chemical properties of the DME are given in Table 3.

\subsection{Characterisation of adsorbents}

\subsubsection{BET and SEM analysis}

Brunauer-Emmett-Teller (BET) and Scanning election microscopy (SEM) techniques were used to analyse the physical properties, surface morphology and chemical composition of the adsorbents. The 
BET analysis was carried out using an advanced Nova system (model: Quantachrome Nova 4000e) with liquid $\mathrm{N}_{2}$ at $-196{ }^{\circ} \mathrm{C}$. Each sample was degassed at $200{ }^{\circ} \mathrm{C}$ for $24 \mathrm{~h}$ to remove any moisture and impurities and to open the pores and then weighed prior to full isotherm BET analysis. It has been often reported that Ar should be used over $\mathrm{N}_{2}$ for the analysis of microporous materials particularly zeolites because of the validity of the monolayer capacity. However, Bae et al. [19] used both gases to determine the surface areas for ultramicroporous materials and found results to be in good agreement. Although there are reservations on the use of $\mathrm{N}_{2}$ for zeolites it is still considered the standard method and particularly useful for comparing surface areas and pore volumes.

In the SEM analysis the samples were coated with gold to improve the conductivity of the electron beams, and then subjected to a vacuum condition in a chamber prior to analysis. The SEM analysis was carried out using energy dispersive x-ray analysis (EDXA) technique (model: Link System 1000 analyser) and a scanner (model: Cambridge Stereoscan 90).

\subsubsection{TGA}

The thermogravimetric analysis (TGA) technique involves thermal treatment of solid in inert atmosphere to give information about the moisture content, adsorbed gases and the thermal stability of the adsorbent. The TGA was carried out for both zeolites using PerkinElmer Pyris 1 instrument. The samples were heated in the presence of nitrogen at a constant flow of $60 \mathrm{ml} \mathrm{min}^{-1}$. The heating was carried at the following sequence (i) heating from 50 to $105{ }^{\circ} \mathrm{C}$ at the rate of $5{ }^{\circ} \mathrm{C} \mathrm{min}{ }^{-1}$ (ii) hold for 5 min at $105{ }^{\circ} \mathrm{C}$ (iii) heating from 105 to $900{ }^{\circ} \mathrm{C}$ at the rate of $5{ }^{\circ} \mathrm{C} \min ^{-1}$ (iv) hold at the final temperature for $15 \mathrm{~min}$ then cool back down to $50{ }^{\circ} \mathrm{C}$ at a rate of $20^{\circ} \mathrm{C} \mathrm{min}$.

\subsection{Adsorption procedure}

Prior to each adsorption run the equipment set-up was subjected to a leak test using nitrogen $\left(\mathrm{N}_{2}\right)$ at $10 \mathrm{~atm}$ for $24 \mathrm{~h}$. The adsorption experiments were carried out at three different temperatures of $20^{\circ} \mathrm{C}$, $30{ }^{\circ} \mathrm{C}$ and $40{ }^{\circ} \mathrm{C}$ and at various incremental pressures within the range of $0-4.0$ atm. At the start the adsorption cell was filled with $\sim 2.5-3.0 \mathrm{~g}$ of adsorbent, approximately filling $90 \%$ of the cell. The cell was then gently tapped down to ensure good solid packing. The whole system with the loaded adsorbent in the adsorption cell was then heated and maintained at the desired temperature while vacuumed for $1 \mathrm{~h}$ to achieve the ultimate vacuum pressure. The adsorption cell and manifold regions were then isolated using valves $\mathrm{MV}_{1-5}$ (see Fig. 1), while the initial pressures and temperatures were recorded $\left(P_{\mathrm{M} 1}, T_{\mathrm{M} 1}\right.$ and $\left.P_{\mathrm{AC} 1}, T_{\mathrm{AC} 1}\right)$. With the adsorption cell isolated the manifold region was then gradually filled by opening valve $\mathrm{MV}_{1}$ with the adsorbate gas being controlled by the flow meter to reach the desired incremental pressure. The manifold temperature and pressure $\left(P_{\mathrm{M} 2}, T_{\mathrm{M} 2}\right)$ were then recorded after reaching constant values (usually within $\sim 1 \mathrm{~min}$ ). Then $\mathrm{MV}_{4}$ between the manifold and 
the adsorption cell was opened and the two regions were allowed to equilibrate before recording the final pressures and temperatures in the two regions $\left(P_{\mathrm{M} 3}, T_{\mathrm{M} 3}\right.$ and $\left.P_{\mathrm{AC} 3}, T_{\mathrm{AC} 3}\right)$. A gas residence time of fifteen minutes was allowed in each incremental pressure, although, in most cases the equilibrium was reach well before that. In analysing the adsorption rate, experiments were carried by introducing one single dose of the DME gas to the adsorption cell at the pressure of $4.0 \mathrm{~atm}$ and temperature of $20^{\circ} \mathrm{C}$. The drop in pressure against time was then recorded for 30 minutes.

\section{Analysis methods}

\subsection{Determination of the adsorption isotherms}

The number of moles of gas adsorbed per mass of the adsorbent $\left(m_{S}\right)$ was calculated as follows:

$$
\Delta n^{e x}=\frac{1}{m_{S}}\left(\Delta n_{M}-\Delta n_{A C}\right)
$$

Where $\Delta n^{e x}, \Delta n_{M}$ and $\Delta n_{A C}$ represent the amount of excess gas adsorbed, the volume of gas released from the manifold and the gas remained free in the adsorption cell after the end of the run (i.e. at equilibrium) respectively. Using the ideal gas law, Eq. 1 can be written as follows:

$$
\Delta n^{e x}=\frac{1}{m_{S}}\left[\left(\frac{P_{M 2}}{z_{M 2} T_{M 2}}-\frac{P_{M 3}}{z_{M 3} T_{M 3}}\right) \frac{V_{M}}{R}-\left(\frac{P_{A C 3}}{z_{A C 3} T_{A C 3}}-\frac{P_{A C 1}}{z_{A C 1} T_{A C 1}}\right) \frac{V_{0}}{R}\right]
$$

where $V_{\mathrm{M}}$ and $V_{0}$ are the volume of the manifold and the void volume in the adsorption cell respectively. The compressibility factors, $z$, at each respective condition were calculated using the Pitzer correlations for the $2^{\text {nd }}$ virial coefficient due to its validity for low to moderate pressures. This is also described by Smith et al. [20] as the most accurate correlation for non and slightly polar molecules. Adsorption in this study was carried out in succession at incremental pressures on the same adsorbent. The final conditions of each incremental pressure $\left[\left(P_{\mathrm{M} 3}, T_{\mathrm{M} 3}\right)\right.$ and $\left.\left(P_{\mathrm{AC} 3}, T_{\mathrm{AC} 3}\right)\right]$ became the new initial conditions $\left(P_{\mathrm{M} 1}, T_{\mathrm{M} 1}\right.$ and $\left.P_{\mathrm{ACl}}, T_{\mathrm{AC} 1}\right)$ for the next subsequent pressure until reaching the maximum pressure of $4.0 \mathrm{~atm}$. In order to construct the adsorption isotherm, the cumulative amount adsorbed at any $i^{\text {th }}$ step, the uptake at each incremental pressure was added as follows:

$$
\left[n_{\text {adsl }}\right]_{i}=\sum_{i=1}^{i} \Delta n_{i}^{e x} \quad i=1,2,3 \ldots
$$

\subsection{Determination of volumes}

For the volumetric adsorption calculation described above it was essential to accurately determine the following volumes:

1. The empty volume of the manifold region $\left(V_{M}\right)$; 
2. The empty volume of the adsorption cell $\left(V_{A C}\right)$;

3. The void volume in the packed adsorption cell $\left(V_{0}\right)$.

All of the volumes were determined by using the well-known helium (He) expansion method. The unknown volumes $V_{M}$ and $V_{A C}$ were determined after filling the adsorption cell with a known volume of non-porous glass beads. The glass beads were used to calibrate the manifold and adsorption cell volumes. The void volume $V_{o}$ is defined as the external void between the molecular sieve particles, excluding the interconnected pores, known as the "interparticle" void volume. In determining $V_{0}$, two major assumptions were made (i) the He does not penetrate into the regions that are inaccessible for the DME (ii) the He is not absorbed or adsorbed by the molecular sieves used. Malbrunot et al. [21] and Ozdemir [22] described that the He adsorption into open and closed pores is negligible. On the other hand, it is largely debateable that the He may actually penetrate readily into the pores, thus is not suitable for such procedures [23]. Due to these conflicting reports and since He has a very small molecular size of $2.2 \AA$ [24], smaller than the pore size in the molecular sieves used in this study, it was important to practically demonstrate the suitability of this method, at least for this particular study. This was carried out by testing and comparing the performance with two other gases: $\mathrm{N}_{2}$ and argon (Ar). Recently, Silvestre-Albero et al. [25] suggested that probe molecules, such as Ar, are more sensitive to the presence of narrow micropores/constrictions for solid characterisation analysis.

\subsection{Heat of adsorption}

The heat of adsorption is an important measure giving an indication of the nature of the adsorbentadsorbate interaction, strength of bonding, surface morphology and pore structure of the adsorbent [26]. The magnitude of the heat released is strongly influenced by the surface coverage $(\theta)$ because this can alter the energetics of adsorption. Through the knowledge of the heat of adsorption, one can distinguish between chemisorption and physisorption. Typically, adsorption is an exothermic process; where a high heat of adsorption in the range of $>40 \mathrm{~kJ} \mathrm{~mol}^{-1}$ is associated with the so called chemisorption and $<40 \mathrm{~kJ} \mathrm{~mol}^{-1}$ is commonly classified as physisorption. In the latter case, the bonding is driven by weak van der Waal (VDW) and electrostatic forces, and so the heat of adsorption is no more than the heat of condensation, thus making this process much easier to reverse, i.e. desorb. In this study, the heat of adsorption at different loadings was determined using two different methods (i) isosteric method based on thermodynamics principles and (ii) calorimetric method based on direct temperature measurements. The isosteric heats of adsorption were calculated using the ClasiusClapeyron equation given by:

$$
\Delta H_{s}=-R\left(\frac{\delta(\ln P)}{\delta\left(\frac{1}{T}\right)}\right)_{\theta}
$$


The calorimetric method was derived from the heat balance around the adsorption cell during adsorption as follows:

$$
d Q_{a d s}=d Q_{s}+d Q_{g_{\text {free }}}+d Q_{g_{\text {ads }}}+d Q_{t h}+d Q_{\text {loss }}
$$

where $Q_{a d s}$ is the total heat released during adsorption and the terms in the right side represent the heat gained by the solid adsorbent $\left(Q_{S}\right)$, the heat gained by the free gas $\left(Q_{g_{\text {free }}}\right)$ surrounding the adsorbent (non-adsorbed gas), the heat gained by the adsorbed gas $\left(Q_{g_{a d s}}\right)$, the heat gained by the thermocouple rod $\left(Q_{t h}\right)$ and the heat loss to the surrounding through the adsorption cell walls $\left(Q_{\text {loss }}\right)$, respectively. Both the temperature and pressure changes were recorded simultaneously as described in the experimental section. An example of the typical recorded data during adsorption experiment is shown in Fig. 4. In deriving Eq. 5, a number of assumptions have been made as follows:

1. Negligible thermal resistance at the solid-gas interphase, hence both phases inside the adsorption cell are assumed to be at instantaneous thermal equilibrium;

2. The recorded temperature during the adsorption represents the temperature of the solid and gas phases $\left(=T_{b}\right)$;

3. The internal wall in the adsorption cell is at thermal equilibrium with the gas/solid phase inside the cell $\left(T_{w}=T_{b}\right)$;

According to these assumptions and the recorded temperature and pressure during adsorption, Eq. 5 can be written to calculate the amount of heat released at any time during the adsorption as follows:

$$
\begin{array}{r}
Q_{a d s}(t)=m_{s} C_{p_{S}} \int_{T_{o}}^{T_{b}(t)} d T_{b}+\left(m_{g_{\text {free }}}+m_{g_{a d s}}\right) C_{p_{g}} \int_{T_{o}}^{T_{b}(t)} d T_{b} \\
+m_{t h} C_{p_{t h}} \int_{T_{o}}^{T_{b}(t)} d T_{b}+h A \int_{t_{o}}^{t}\left[T_{b}(t)-T_{a m b}\right] d t
\end{array}
$$

where $m_{S}, m_{g_{\text {free }}}, m_{g_{a d s}}$ and $m_{t h}$ are the masses of the adsorbent, the free DME gas, the adsorbed DME gas and the thermocouple respectively. $C_{p_{S}}, C_{p_{g}}$ and $C_{p_{t h}}$ are the specific heat capacities of the molecular sieves, the DME gas and the thermocouple rod respectively. $T_{b}$ is the bulk temperature, $t$ is the time, $h$ is the heat transfer coefficient and $A$ is the heat transfer area. The cumulative calorimetric heat of adsorption in units of $\mathrm{KJ} \mathrm{mol}^{-1}$ is then given by adding the heat released at incremental pressure divided by the cumulative moles of the DME adsorbed ( $n_{\text {ads }}$ ) such that:

$$
\left[\Delta H_{s}\right]_{i}=\frac{\sum_{i=1}^{i}\left[Q_{a d s}\left(t_{\max }\right)\right]_{i}}{\left[n_{\text {ads }}\right]_{i}}
$$


In estimating the heat transfer coefficient used in Eq. 6, the equation for natural convection from a vertical heated plate was used as follows:

$$
h=\frac{N u k}{L}=\delta R a^{\gamma}
$$

where the constants $\delta$ and $\gamma$ are taken as 0.1 and 0.33. The Rayleigh number is expressed in terms of Grashof and Prandtl numbers as follows:

$$
R a=G r \operatorname{Pr}=\frac{g \rho^{2} \beta C_{p}\left(T_{w}-T_{a m b}\right) L^{3}}{\mu k}
$$

Fig. 5 shows example of the calculated heat transfer quantities given in the right hand side of Eq. 5 for a selected adsorption test on Mol5A. It is clear that majority of the heat of adsorption is associated with raising the solid adsorbent temperature, due to its high heat capacity.

\section{Results and discussions}

\subsection{Characterisation of adsorbents}

\subsubsection{BET and SEM analysis}

Table 4 shows the results of BET analysis of the surface area and pore volume for the adsorbents. Compared to Mol4A, Mol5A has a substantially larger total surface area, which consists mainly of micropores. The EDXA analysis shown in Table 5 compares the elementary compositions of both adsorbents. It can be seen that oxygen is a major element in both adsorbents, but Mol4A contains less calcium and more sodium as opposed to Mol5A, which supports the chemical composition formula given in Table 2. At low temperature $\leq 27^{\circ} \mathrm{C}$, the high oxygen content is desirable as it allows for the adsorption and dissociation of DME into methoxy species on the surface of the particles [24]. Both adsorbents have a low Si/Al ratio, which according to Semelsberger [27] and Jiang [12], is also a desirable chemical property for high DME uptake.

Fig. 6a shows the SEM images for both adsorbents prior to adsorption at low magnification. It can be seen that Mol4A is a relatively more spherical with what appears to be a smooth surface, whereas Mol5A has an irregular shape with sharp edges. Mol4A particles are much larger in size $\sim 2000 \mu \mathrm{m}$ while Mol5A particles are in the range of $350-500 \mu \mathrm{m}$ in size. Fig. $6 \mathrm{~b}$ shows images at higher magnification prior to and post adsorption. Prior to adsorption Mol4A shows limited porosity whereas Mol5A is significantly more porous with cracks and cavities present. This lends support to the BET analysis, which shows a considerable larger surface area for Mol5A. Both Mol4A and Mol5A post adsorption show some evidence of adsorbate molecules on the surface from the lighter discoloration of the images due to DME coverage. The cracks and pores are also less apparent and the surface is much smoother, especially on Mol5A. It must also be taken into consideration that adsorbed images 
show limited adsorption since the adsorbed molecules would have desorbed when exposed to atmosphere and during preparation for analysis.

\subsubsection{TGA}

Fig. 7 shows the weight loss and its derivative for both adsorbents after heating up to $900{ }^{\circ} \mathrm{C}$. The weight loss curves for both zeolites exhibit similar trends with the rapid mass loss taking place within the temperature range of $<200{ }^{\circ} \mathrm{C}$. At $100{ }^{\circ} \mathrm{C}$ the adsorbents lost around $\sim 5 \%$ of their original masses, which can mainly be attributed to the evaporation of surface free moisture. This corresponds to the first peak in the differential weigh loss curve. From $100-200{ }^{\circ} \mathrm{C}$ both sorbents show additional weight loss of $\sim 10 \%$, most probably due to desorption of occluded moisture and other gases, however, the differential loss is slightly different with Mol4A showing a second peak occurring at a lower temperature of $\sim 150{ }^{\circ} \mathrm{C}$. In the temperature range of $>200{ }^{\circ} \mathrm{C}$, both adsorbents show negligible mass losses, thus indicating reasonable thermal stability at elevated temperature. This is in agreement with the results of Knowlton and White [28] where it was reported that there are at least three types of water present in zeolites: crystal water, loosely bound water and tightly held water. The first two were reported to be easily removed within the temperature range of $50-200{ }^{\circ} \mathrm{C}$. In terms of DME adsorption, it is plausible that a limited amount of moisture could play an important role in the adsorption process through the formation of strong bonds between the ether oxygen atom in the DME and the hydroxyls at the adsorbent surface. This may also increase DME adsorption due to its high solubility in water $(6.9 \mathrm{~g} / 100 \mathrm{~g})$.

\subsection{Volumes of the system}

The manifold and the empty adsorption cell volumes were found to be $20.22 \mathrm{~cm}^{3}$ and $9.02 \mathrm{~cm}^{3}$ respectively. The void volumes, $V_{0}$, in the adsorption cell after filling with Mol4A and Mol5A particles were $8.01 \mathrm{~cm}^{3}$ and $7.97 \mathrm{~cm}^{3}$, respectively. In order to confirm the validity of the $\mathrm{He}$ expansion in determine the volumes, Fig. 8 compares the results of adsorption isotherms calculated at $20{ }^{\circ} \mathrm{C}$ using three different gases of $\mathrm{He}, \mathrm{N}_{2}$ and $\mathrm{Ar}$ with Mol5A in the adsorption cell. The reported critical diameters of these gases are: He, $2.2 \AA$; N2, $3.1 \AA$ and Ar, $3.8 \AA$ [20, 29]. It is shown that, while the $\mathrm{N}_{2}$ and Ar both adsorb substantially with quantitates respective to their molecular size, the He shows no adsorption at low pressure and very limited and negative amount as the pressure increases, which is an indication of surface depositions. The same behaviour was also evident when working with Mol4A. These results confirm that the applicability of $\mathrm{He}$ expansion technique in determining the void volumes. 


\subsection{Adsorption isotherms and modelling}

Fig. 9 shows the adsorption isotherms for DME on Mol4A and Mol5A at 20, 30 and $40{ }^{\circ} \mathrm{C}$ and the corresponding fitting model. Adsorption on Mol4A shown in Fig. 9a exhibits trends typical of a Type II isotherm (often referred to as sigmoid isotherms). Type II isotherms are commonly observed with microporous solids or those exhibiting limited porosity. Such curves are characterised by a steady increase in the adsorption capacity with increasing pressure. The observed inflection point in the curve (at $\sim 1.0 \mathrm{~atm}$ ) represents the transition from complete monolayer to multilayer adsorption. The adsorption isotherm on Mol5A, shown in Fig. 9b, exhibited similarities with Type I and III isotherms. Type III behaviour is depicted by the slight convex in the adsorption curve at low pressure, which indicates a low gas-solid affinity at low pressure followed by rise in adsorbate-adsorbate interactions promoting further adsorption, thus giving the similarity with Type I adsorption at pressure $>1.0 \mathrm{~atm}$.

Within the conditions considered in this study, the maximum adsorption capacity at $20^{\circ} \mathrm{C}$ on Mol5A was found to be $2.68 \mathrm{~mol} \mathrm{~kg}^{-1}\left(123.4 \mathrm{mg} \mathrm{g}^{-1}\right)$, which is more than eight times higher than the adsorption capacity on Mol4A at the same temperature and pressure range. The significantly reduced adsorption capacity with Mol4A can be mainly attributed to the differences in surface area, micropore volume and pore size. Mol4A has no microporous volume and a smaller pore size than Mol5A, thus the adsorption is most likely limited to mono or multilayer formation. Adsorption on Mol5A is believed to follow a pore filling mechanism since its pore diameter is large enough for DME molecules to penetrate.

Mol4A showed that low temperatures were favoured for increased adsorption. This behaviour can be explained by the Le Chatelier's principle, meaning endothermic desorption is possible when temperature increases, hence less DME adsorption at higher temperature. This is plausible since the homogenous and flat surface of Mol4A makes it much easier for DME to desorb as its density changes with temperature. In contrast, adsorption on Mol5A appears to be insensitive to temperature, at least within the rage considered here. Hypothetically, this could be due to the (i) DME molecules predominantly locked inside the pores and therefore unlikely to desorb easily, especially within this limited temperature range (ii) DME dissolving in the occluded moisture thus creating bond far strong for such a low temperature to have effect.

Since the adsorption test were carried out within a moderate range of pressure it was appealing to fit the adsorption isotherms with the widely used Freundlich empirical model given by:

$$
n_{a d s}=K p^{1 / \alpha}
$$


This model is generally applicable for the description of adsorption of liquid organic compounds and gases onto activated carbon and zeolites particularly that of heterogeneous surfaces [30]. As shown in Fig. 9, the model fitted reasonably well the experimental data within the conditions considered. In the case of Mol4A (Fig. 9a), the effect of temperature on the adsorption isotherm was incorporated in the model by expressing the equilibrium parameters $K$ and $\alpha$ as function of temperature as follows:

$$
\begin{gathered}
K=k_{1} \exp \left(\frac{-E_{a}}{R T}\right) \\
\alpha=k_{2}\left(\frac{T}{T_{\text {ref }}}\right)^{m}
\end{gathered}
$$

Least square method of non-linear regression was used to obtain the model fitting parameters. The activation energy in Eq. $11\left(E_{a}\right)$ was obtained from the Arrhenius plot shown in Fig. 10. The adsorption isotherms for Mol5A were found to be independent of temperature, as discussed earlier. Therefore Eq. 10 was fitted to constant parameters independent of temperature. All values of the fitting parameters in Eqs. 10-12 are given in Table 6.

The effect of thermal and vacuum pre-treatment on adsorption isotherm is shown in Fig. 11. Both adsorbents were heated to $150{ }^{\circ} \mathrm{C}$ in ultimate vacuum for $24 \mathrm{~h}$ before being subjected to DME adsorption. This was compared to the standard pre-treatment at ambient temperature and $1 \mathrm{~h}$ vacuum. Clearly, there is limited increase in adsorption capacity by only $6.69 \%$ on Mol4A (Fig. 11a) and $2.79 \%$ on Mol5A (Fig. 11b). This can be attributed to the increase in pores openings as a result of thermal removal of bonded volatiles and occluded moisture within the adsorbent structure. This was earlier confirmed by the TGA results (see Fig. 7), where a limited mass loss was observed at this temperature.

\subsection{Adsorption Kinects}

Understanding the adsorption kinetics is critically important for the design of an adsorption process. For example, a separation process based on pressure or vacuum swing adsorption requires precise knowledge of the adsorption rate and time scale for equlibrium. In this part of the study, the kinetics of DME adsorption on Mol4A and Mol5A was investigated by plotting the adsorption rate against time as shown in Fig. 12. Compared to Mol4A, Mol5A appears to show a slower adsorption in the longer time scale. There is hardly a noticeable difference within the first $20 \mathrm{~s}$, which suggests similarity in the adsorption mechanism in both adsorbent at this early stage. Mol4A reaches equilibrium faster and hence the adsorption ceases earlier. This interesting results lead to further investigations on the adsorption mechanisms at various time scales as discussed below. 
Ruthven et al. [31] reported that molecules can be adsorbed on zeolite governed by intracrystalline diffusion or surface layering. Cheung et al. [32] reported that the intracrystalline diffusion and surface layering mechanisms in the initial stage can be distinguished by distinct linear relations expressed in terms of the fractional coverage, $n / n_{\max }$, and adsorption time, $t_{a d s}$, as follows: intracrystalline diffusion controlled:

$$
\frac{n}{n_{\max }}=B_{1} \sqrt{t_{a d s}}
$$

Surface layering controlled:

$$
\ln \left[1-\frac{n}{n_{\max }}\right]=B_{2} t_{a d s}
$$

where $B_{1}$ and $B_{2}$ are constants and $t_{a d s}$ is the time of adsorption in seconds. At a long time scale, the liner relation of Eq. 14 is valid only if the adsorption mechanism is controlled by diffusion or heat transfer [32]. Fig. 13 show the plots of the above functions for Mol4A and Mol5A for adsorption experiments conducted at the starting pressure of $4.0 \mathrm{~atm}$ and ambient temperature of $20{ }^{\circ} \mathrm{C}$. At a short time scale, within the first 10 seconds, Fig. 13a shows that the loading in both adsorbents follow a linear dependence on $\sqrt{t_{a d s}}$, thus indicating that the DME adsorption kinetics are controlled by diffusion. At a longer time scale, Fig. 13b shows that the adsorption kinetics on Mol4A deviates from linearity with respect to time, hence suggesting surface resistance controlled diffusion. This is in good agreement with the earlier isotherm analysis where Type II adsorption behaviour was observed. Contrastingly, Mol5A depicts a relatively linear relation with time, as shown in Fig. 13b, hence suggesting intercrystiline diffusion mechanism. Again, this is supporting the earlier BET data where it is shown that Mol5A is significantly more microporous than Mol4A.

\subsection{Heats of adsorption}

Fig. 14 shows the heat of adsorption for triplicated data from DME adsorption on Mol4a and Mol5A at $20{ }^{\circ} \mathrm{C}$ using the calorimetric method. The heat of adsorption on Mol4A (Fig. 14a) shows a steady decrease in the heat of adsorption within the low range of loading followed by a nearly consistent value of around $6.5 \mathrm{~kJ} \mathrm{~mol}^{-1}$. A similar trend is observed with Mol5A (Fig. 14b) at low loading, but with a rather steeper dip in heat of adsorption reaching a consistent value around $\mathrm{kJ} \mathrm{mol}^{-1}$. The highest measured values for the heats of adsorption were 25.8 and $20.1 \mathrm{~kJ} \mathrm{~mol}^{-1}$ for Mol4A and Mol5A, respectively. Interestingly, these values are close to the heat of condensation of DME $\left(21.5 \mathrm{~kJ} \mathrm{~mol}^{-1}\right.$ at $25.0^{\circ} \mathrm{C}$ ), thus suggesting physisorption binding energy, arising from weak VDW's forces between the adsorbate molecules and the adsorbent surface. Kowalczyk et al. [33] described that the heat of adsorption arises from the contribution of adsorbent-surface interaction (A-S) and adsorbent- 
adsorbent interaction (A-A). The results shown in Fig. 14 suggest that the high heat of adsorption at low pressure and low coverage is mainly due to the initial interaction with the vacant solid surface. The adsorbate molecules initially adsorb onto the high energy adsorption sites, thus giving rise to the initially high heat values. Once these sites are filled, adsorption proceeds on less energy sites until the monolayer is complete [34]. At higher loadings, the A-S interactions become weak and are replaced by a nearly constant A-A interactions [35], as clearly demonstrated in these figures.

The calorimetric heats of adsorption are compared with the isosteric heats in Table 7. The isosteric heats were calculated from the isotherms data obtained at the temperature range of $20-40{ }^{\circ} \mathrm{C}$, while the calorimetric heats were obtained at ambient temperature of $20^{\circ} \mathrm{C}$. The calorimetric method gave higher heats of adsorption and a relatively better agreement with the isosteric heats in the case of Mol4A. The great discrepancy in the case of Mol5A, where considerably low isosteric heats of adsorption are observed, is mainly due to the negligible variation of the adsorption isotherms within the range of temperature considered, thus making the values obtained by the isosteric method questionable. In a study by Shen et al. [36], it was shown that the calorimetric heats are always slightly higher than the heat from the isosteric method. While no clear reasons were given, it was suggested that the temperature variations between the two methods may have played a role. On the contrary, a study by Garbacz et al. [16], also comparing the calorimetric approach with the isosteric method, reported considerable differences between the heats calculated by the two methods. It was concluded that the calorimetric method is unsuitable for trustworthy analysis for the system they considered. They attributed this to the strongly restricted molecules diffusion resulting from the existence of very narrow pores in their adsorbents.

\section{Conclusions}

The adsorption of DME on two different types of molecular sieves (Mol4A and Mol5A) at low pressure range $(<4.0 \mathrm{~atm})$ has been experimentally investigated using the volumetric method. The adsorption isotherms, heats of adsorption and the adsorption kinetics and mechanisms within the temperature ranges of $20-40{ }^{\circ} \mathrm{C}$ have been presented and discussed. The heat of adsorption was determined by a calorimetric method (using direct temperature measurements) and compared with the

isosteric method (using the Clasius-Clapeyron equation). Based on the analysis and the comparison between the two adsorbents performance the following conclusions are drawn:

- Mol5A has an adsorption capacity over eight times higher than Mol4A. This is mainly due to Mol5A being of larger surface area and pore volume, of higher surface heterogeneity and of bigger pore sizes.

- Adsorption at low temperature is favourable for increased adsorption capacity with Mol4A.

On the contrary, Mol5A have shown negligible variation in adsorption capacity within the 
range of $20-40{ }^{\circ} \mathrm{C}$. Thermal pre-treatment in vacuum of the adsorbents at $150{ }^{\circ} \mathrm{C}$ for $24 \mathrm{~h}$ increased the adsorption capacities by $6.69 \%$ and 2.79\% on Mol4A and Mol5A, respectively.

- The adsorption on Mol4A exhibits Type II isotherm, thus indicating a monolayer to multilayer adsorption. The adsorption on Mol5A, which is believed to be dominated by pore filling mechanism, exhibits similarity with a Type III isotherm within the low pressure range and Type I isotherms at a pressure higher than $\sim 1.0 \mathrm{~atm}$. All adsorption isotherms data were fitted to the Freundlich empirical model and the corresponding fitting parameters were proposed.

- The adsoprtion kinetic analysis suggest that the DME is adsorbed on Mol5A controlled by intracrystalline diffusion resistance, while adsorption on Mol4A is mainly controlled by surface layering resistance with the diffusion resistance taking place only during the start of the adsorption and for a very limited short time. The adsorption rate for both adsorbents was comparable within the first $20 \mathrm{~s}$ of adsorption; however Mol4A was found to reach equilibrium much faster due to its limited capacity compared to Mol5A.

- The highest calorimetric heats of adsorption for both adsorbents occurred at the minimum loading and this was found to be around $25.0 \mathrm{~kJ} \mathrm{~mol}^{-1}$, thus suggest a physisorption type of interaction dominated by weak van der Waal's (VDW) forces. For both adsorbents, the heat of adsorption dropped sharply with increasing pressure to reach consistent values within the range of 4.0-7.0 $\mathrm{kJ} \mathrm{mol}^{-1}$.

- Although the heat balance approach (calorimetric method) and thermodynamic approach (isosteric method) are both theoretically correct in calculating the heats of adsorption, the results obtained with the latter method should be treated with caution if the adsorption isotherms show little variations with temperature.

\section{Acknowledgments}

This work was supported by the Engineering and Physical Research Council, UK (EPSRC).

\section{Nomenclature}

A

A

$C_{\mathrm{P}}$

$E_{a}$

F

$g$

Gr

$h$ angstroms

heat transfer area $\left(\mathrm{m}^{2}\right)$

specific heat Capacity $\left(\mathrm{kJ} \mathrm{kg}^{-1} \mathrm{~K}^{-1}\right)$

activation energy $\left(\mathrm{kJ} \mathrm{mol}^{-1}\right)$

flow meter

gravitational acceleration $\left(\mathrm{m} \mathrm{s}^{-2}\right)$

Grashof's number (-)

heat transfer coefficient $\left(\mathrm{W} \mathrm{m}^{-2} \mathrm{~K}^{-1}\right)$ 


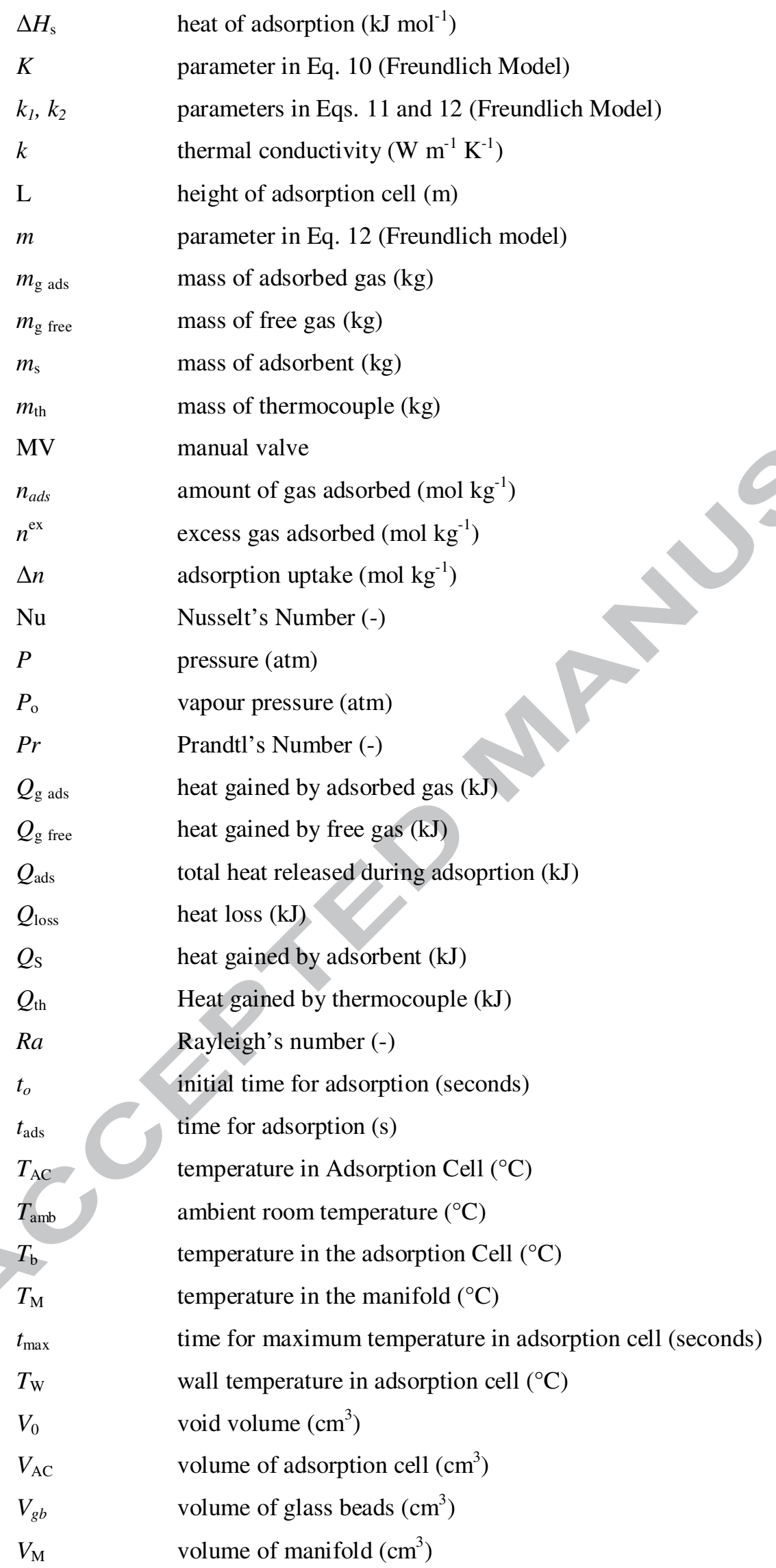


z compressibility factor (-)

Greek symbols

$\begin{array}{ll}\beta & \text { coefficient of Thermal Expansion (-) } \\ \mu & \text { dynamic Viscosity }\left(\mathrm{m}^{2} \mathrm{~s}^{-1}\right) \\ \rho & \text { density }\left(\mathrm{kg} \mathrm{m}^{-3}\right) \\ \alpha & \text { parameter in Eq. } 10 \text { (Freundlich Model) } \\ \theta & \text { adsorbent coverage }\left(=n / n_{\max }\right) \\ \delta, \gamma & \text { parameters in Eq. } 8(-)\end{array}$

\section{References}

[1] Triebe, R.W., Tezel, F.H., Khulbe, K.C., Adsorption of methane, ethane and ethylene on molecular sieve zeolites. Gas Separation \& Purification, 1996. 10(1): p. 81-84.

[2] Lamia, N., Granato, M., Gomes, P., Grande, C., Wolff, 1., Leflaive, P., Propane/Propylene separation by simulated moving bed II. Measurement and prediction of binary adsorption equilibria of Propane, Propylene, Isobutane and 1-Butene on 13X zeolite. Separation Science and Technology, 2009. 44: p. 1485-1509.

[3] Liu, D., Yaoa, C., Zhanga, J., Fanga, D., Chenb, D., Catalytic dehydration of methanol to dimethyl ether over modified $\gamma$-Al2O3 catalyst. Fuel, 2011. 90: p. 1738-1742.

[4] Jiang, S., Hwang, J-S, Jin, T., Cai, T., Cho, W., Back, Y., Park, S-E., Dehydration of methanol to dimethyl ether over ZSM-5 zeolite. Bulletin of the Korean Chemical Society, 2004. 25(2): p. 185-189.

[5] Tan, Y., et al., Modification of Cu-based methanol synthesis catalyst for dimethyl ether synthesis from syngas in slurry phase. Catalysis Today, 2005. 104(1): p. 25-29.

[6] Wang, T., Li, Y., Ma, L., Wu, C., Biomass to dimethyl ether by gasification/synthesis technology - an alternative biofuel production route. Energy, 2011. 5(3): p. 330-339.

[7] Li, H., He, S., Ma, K., Wu, Q., Jiao, Q., Sun, K., Micro-mesoporous composite molecular sieves H-ZSM-5/MCM-41 for methanol dehydration to dimethyl ether: Effect of SiO2/A12O3 ratio in H-ZSM-5. Applied Catalysis B: Environmental, 2013. 450: p. 152-159.

[8] Borgmann, W., Kunkel, J., Fritz, H., Lauermann, G., Walzl, R., Muller, K., Methods for separating dimethyl ether from an olefin-containing product stream. 2003: USA.

[9] Robinson, E., Ross, R.A., Sorption of dimethyl ether on silica gel. Canadian Journal of Chemistry, 1970. 48: p. 13-16.

[10] Anderson, J.A., Rochester, C.H., Infrared study of the adsorption of 1,2-Dimethoxyethane on silica. Journal of the Chemical Society, Faraday Transactions 1, 1989. 85(10): p. 3505-3512. 
[11] Kobayashi, Y., et al., Adsorption isotherms of methanol and dimethyl ether on SAPO-34 measured together with differential adsorption heat measurement. Chinese Journal of Catalysis, 2013. 34(12): p. 2192-2199.

[12] Jiang, X.Z., In-situ FTIR studies of dimethyl ether adsorption on H-ZSM-5 zeolites. Chinese Journal of Chemistry, 1996. 14: p. 497-505.

[13] Forester, T.R., Howe, R.F., In situ FTIR studies of methanol and dimethyl ether in ZSM-5. Journal of the American Chemical Society, 1987. 109: p. 5076-5082.

[14] Reyes, S.C., Krishnan, V.V., Demartin, G.J., Sinfelt, J.H., Strohmaier, K.G., Santiesteban, J.G., , Separation of methanol, ethanol and/or dimethyl ether from hydrocarbon mixtures. 2005.

[15] Dominquez, G., Hernandez-Huesca, R., Arguilar-Armenta, G., Isosteric heats of adsorption of N2O and NO on natural zeolites. Journal of The Mexican Chemistry Society, 2010. 54: p. 111-116.

[16] Garbacz, J.K., Rychlicki, G., Terzyk, A.P., A comparision of isosteric and differential heats of gas adsorption on microporous active carbons. Adsorption Science and Technology, 1994. 11: p. $15-29$.

[17] Walker, P.L., Lamond, T.G., Metcalfe, J.E., The preparation of 4A and 5A carbon molecular sieves. Carbon and Graphite, 1966: p. 7-12.

[18] El-Nahas, A.M., Uchimaru, T., Sugie, M., Tokuhashi, K., Sekiya, A., Hydrogen abstraction from dimethyl ether (DME) and dimethyl suphide (DMS) by OH radical: A computational study. Journal of Molecular Structure: THEOCHEM, 2005. 722(1-3): p. 9-19.

[19] Bae, Y.-S., Yazaydm, A.O., Snurr, R.Q., Evaluation of the BET method for determining surface areas of MOFs and zeolites that contain ultra-micropores. Langmuir, 2010. 26(8): p. 54755483.

[20] Smith, J., Van Ness, H., Abbott, M., Introduction to Chemical Engineering Thermodynamics. Chemical International Edition. 2005, New York: McGraw-Hill

[21] Malbrunot, P., Vidal, D., Vermesse, J., Adsorbent helium density measurement and its effect on adsorption isotherms at high pressure. Langmuir, 1997. 13: p. 539-544.

[22] Ozdemir, E., Chemistry of the adsorption of carbon dioxide by argonne premium coals and a model to simulate CO2 sequestration in coal seams, in School of Engineering. 2004, University of Pittsburgh.

[23] Webb, P.A., Introduction to chemical adsorption analytical techniques and their applications to catalysis. MIC Technical Publications, 2003: p. 1-10.

[24] Setoyama, N., Kaneko, K., Density of He adsorbed in micropores at 4.2K. Adsorption, 1995. 1: p. 165-173.

[25] Silvestre-Albero, J., Silvestre-Albero, A., Llewellyn, P., Rodriguez-Reinoso, F., High resolution $\mathrm{N} 2$ adsorption isotherms at $77.4 \mathrm{~K}$ : Critical effect of the He used during calibration. The Journal of Physical Chemistry 2013: p. 16885-16889. 
[26] Nguyen, C., Do. D.D. , Heat of desorption measure by means of electrical heat excitation. Langmuir, 2001. 17: p. 2287-2290.

[27] Semelsberger, T.A., Steam reforming of dimethyl ether for generating hydrogen-rich fuel-cell feeds, in Chemical Engineering. 2005, Case Western Reserve.

[28] Knowlton, G.D., White, T.R., Thermal study of types of water associated with clinoptilolite Clays and Clay Minerals, 1981. 29: p. 403-411.

[29] Keller, J.U., Staudt, R., Experimental Methods and Adsorption Isotherms. 2005, Boston, USA: Springer Science + Business Media Inc.

[30] Ho, Y., Porter, J., McKay, G., Equilibrium isotherm studies for the sorption of divalent metal ions onto Peat: Copper, Nickel and Lead single component systems. Water, Air and Soil Pollution, 2002. 144: p. 1-33.

[31] Ruthven, D.M., Diffusion in type A zeolites: New insights from old data. Microporous and Mesoporous Materials, 2012. 162(0): p. 69-79.

[32] Cheung, O., et al., Adsorption kinetics for $\mathrm{CO} 2$ on highly selective zeolites NaKA and nanoNaKA. Applied Energy, 2013. 112(0): p. 1326-1336.

[33] Kowalczyk, H., Rychlicki, G., Terzyk, A.P., Low coverage adsorption of methanol, ethanol and carbon tetrachloride on homo and heterogeneous surface. Differential heat and intergral molar entropy. Polish Journal of Chemistry, 1993. 67: p. 2019-2028.

[34] Wang, Y., Hashim, M., Ercan, C., Khawajah, A., Othman, R., High pressure methane adsorption on granular activated carbons. Catalysts in Petroleum Refining \& Petrochemicals, 2011: p. $1-8$.

[35] Steele, W.A., Bojan, M.J., Computer simulation studies of the heats of adsorption of simple gases. Pure Applied Chemistry, 1989. 61: p. 1927-1932.

[36] Shen, D., Bulow, M., Comparison of experimental techniques for measuring isosteric heat of adsorption. Adsorption 6, 2000: p. 275-286.

\section{List of figures}

Fig. 1. Simplified schematic diagram of the manifold and adsorption cell.

Fig. 2. Photo of the experimental adsorption system.

Fig. 3. Chemical structure of DME.

Fig. 4. An example of the variations in temperature and pressure inside the adsorption cell during adsorption on Mol5A.

Fig. 5. An example of the calculated heat transfer during adsorption with Mol5A.

Fig. 6. SEM images of the molecular sieves morphology prior to and post adsorption, (a) low magnification prior to adsorption Mol4A (A) and Mol5A (B); (b) prior to adsorption at higher magnification Mol4A (C) and Mol5A (D); post DME adsorption Mol4A (E) and Mol5A (F). 
Fig. 7. TGA of mass and derivative weight loss versus temperature for Mol4A and Mol5A.

Fig. 8. Adsorption isotherms for helium, nitrogen and $\operatorname{argon}$ on Mol5 A at $20^{\circ} \mathrm{C}$.

Fig. 9. DME Adsorption isotherms fitted to Freundlich models at 20, 30 and $40{ }^{\circ} \mathrm{C}$ on (a) Mol4A and (b) Mol5A.

Fig. 10. Dependence of the Freundlich model parameter $K$ on temperature for Mol4A.

Fig. 11. Effect of thermal and vacuum pre-treatment of adsorbents on the adsorption isotherms (a) Mol4A (b) Mol5A.

Fig. 12. The adsorption rate against time for Mol4A and Mol5A.

Fig. 13. Adsorptive mechanism for Mol4A and Mol5A (a) [1- $\left.\left(n / n_{\mathrm{s}}\right)\right]$ versus $\sqrt{ } t$, where liner relation indicates adsorption controlled by intracrystalline diffusion; (b) $\ln \left[1-\left(n / n_{\mathrm{s}}\right)\right]$ versus $t$, where deviation from linearity indicates adsorption controlled by surface resistance.

Fig. 14. Calorimetric heat of adsorption as a function of DME loading for (a) Mol4A and (b) Mol5A.

\section{List of tables}

Table 1. Key reported studies on DME adsorption.

Table 2. Adsorbent physical and chemical properties.

Table 3. Adsorbate physical and chemical properties.

Table 4. BET surface area and pore volume analysis for Mol4A and Mol5A.

Table 5. EDXA analysis of chemical constituents for Mol4A and Mol5A.

Table 6. Fitting parameters of the Freundlich empirical model for DME on Mol4A and Mol5A.

Table 7. Heats of adsorption of DME on Mol4A and Mol5A calculated by the calorimetric and isosteric methods (Clasius-Clapeyron. 


\begin{tabular}{|c|l|}
\hline $\mathrm{F}$ & Flow meter \\
\hline $\mathrm{MV}$ & Manual Valve \\
\hline $\mathrm{P}$ & Pressure Gauge \\
\hline $\mathrm{T}_{\mathrm{Ac}}$ & Temperature in Adsorption Cell \\
\hline $\mathrm{T}_{\mathrm{M}}$ & Temperature in Manifold \\
\hline$V_{\mathrm{AC}}$ & Volume of Adsorption Cell \\
\hline$V_{\mathrm{M}}$ & Volume of Manifold \\
\hline $\mathrm{VP}$ & Vacuum Pump \\
\hline
\end{tabular}

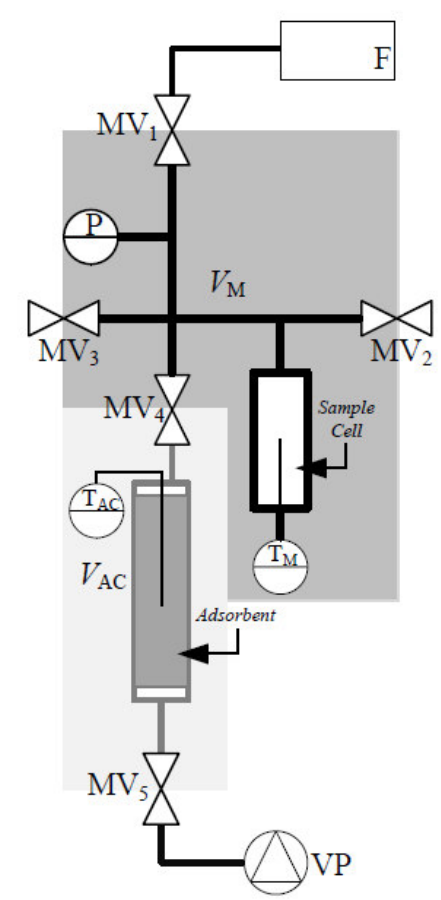




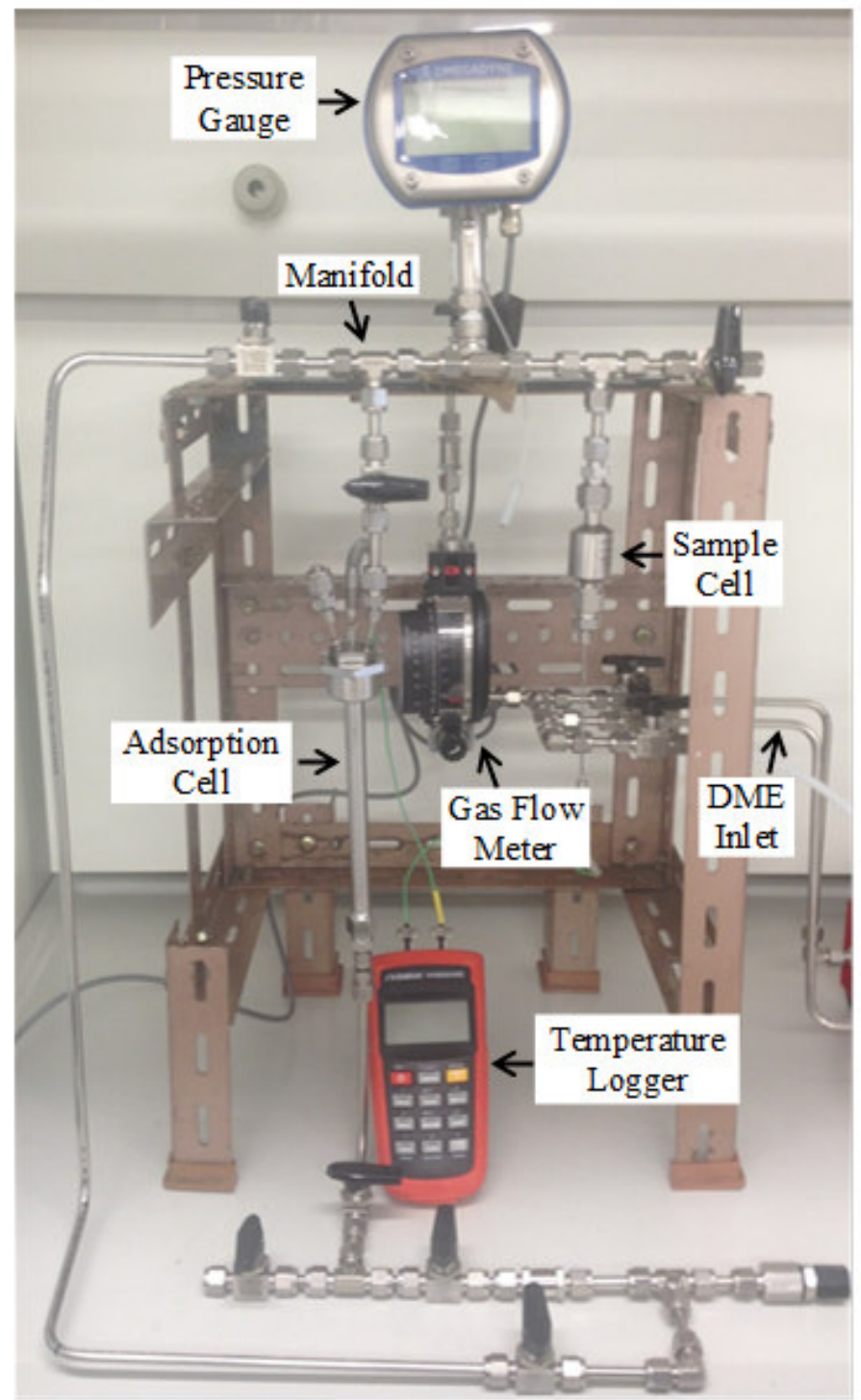



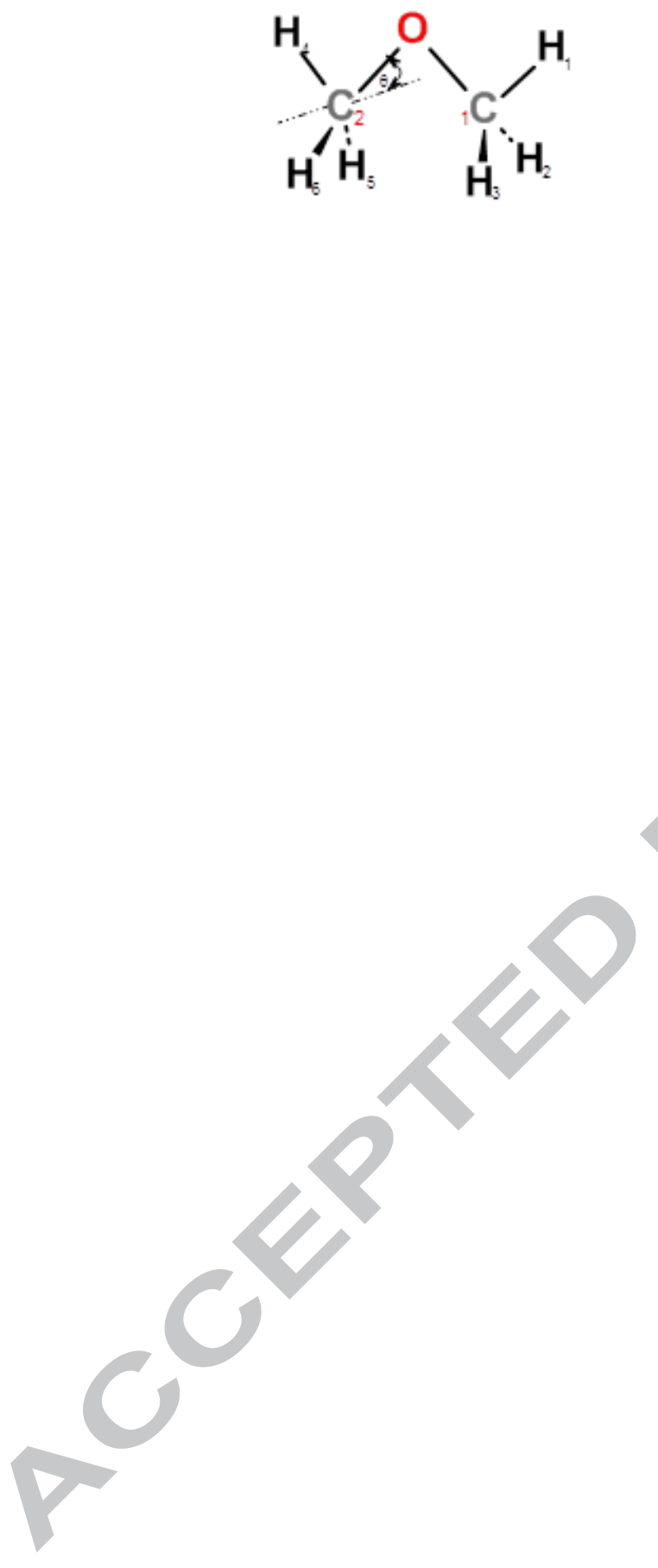


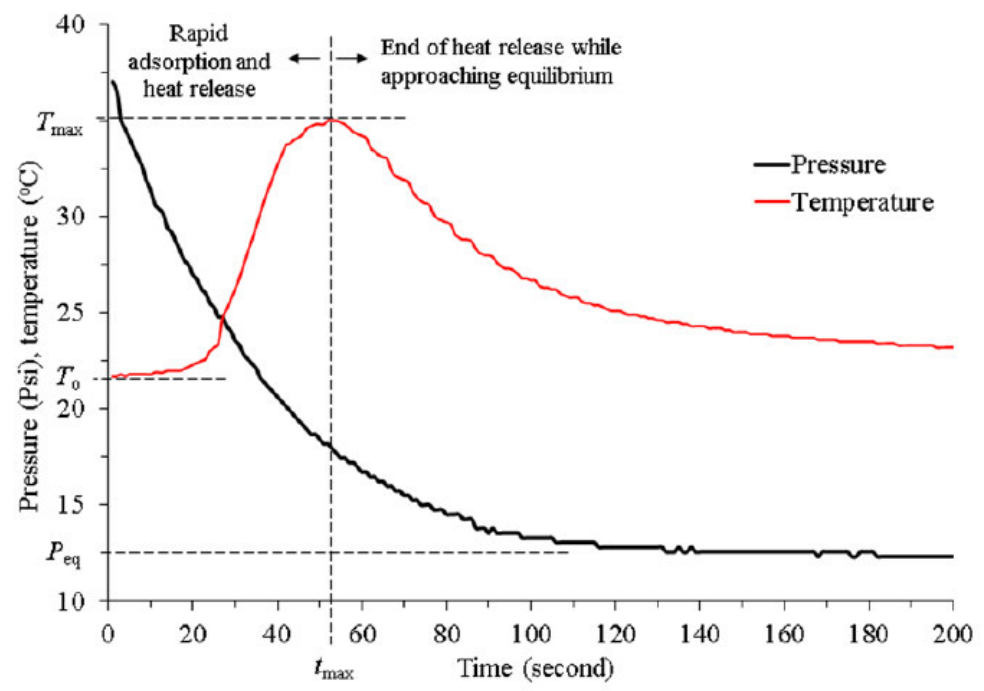




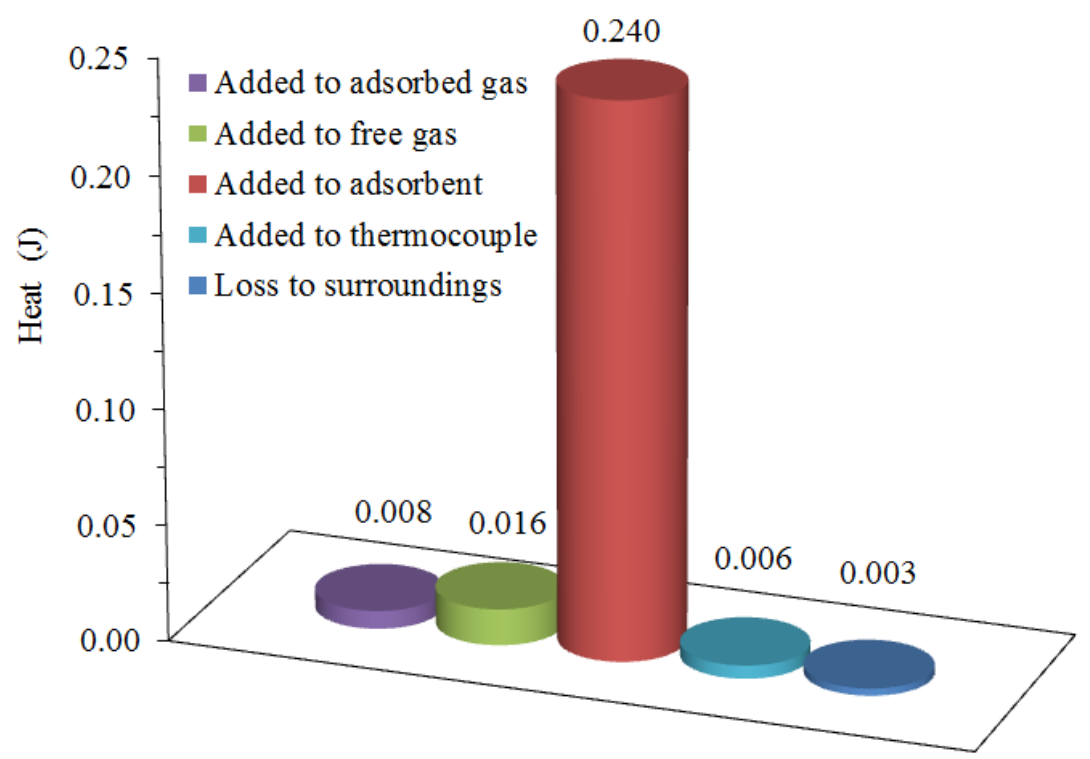



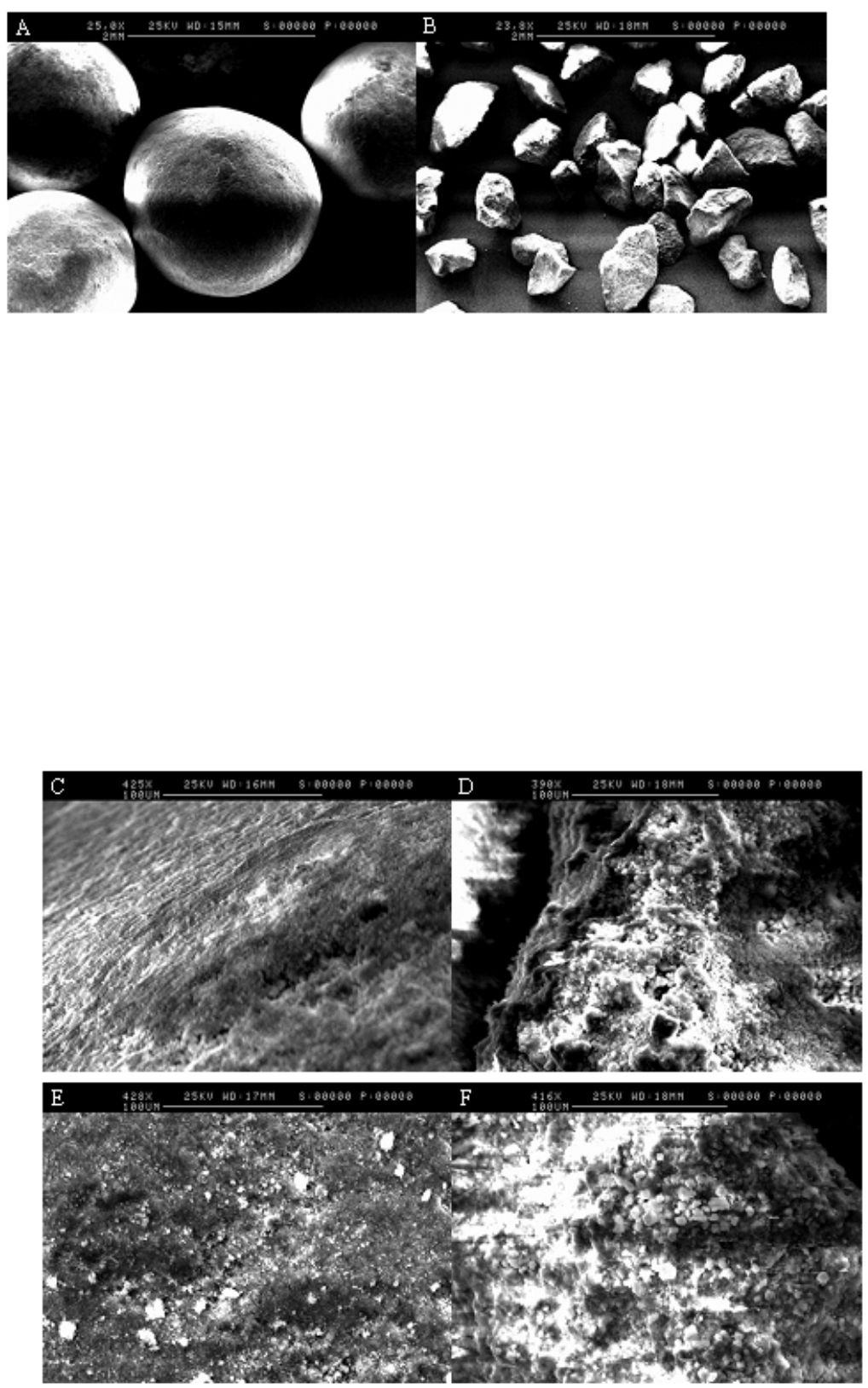


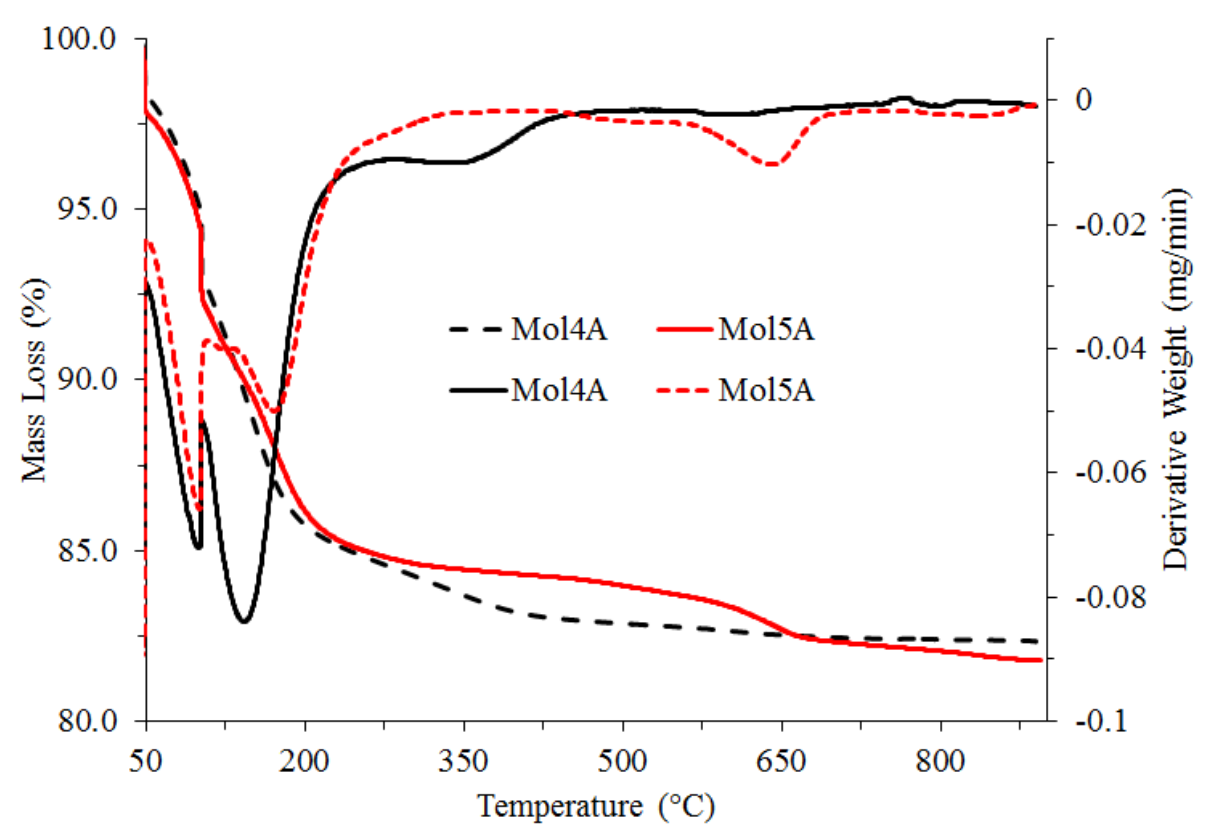




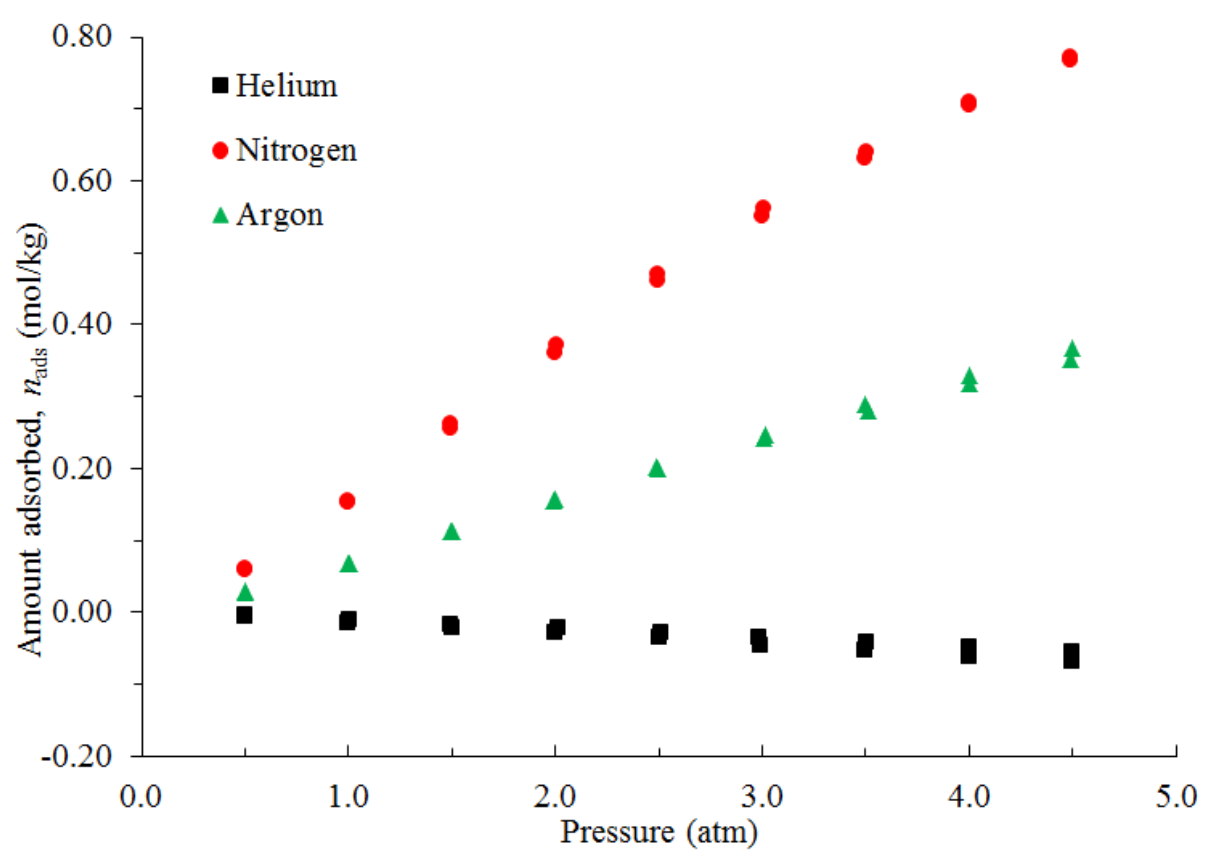



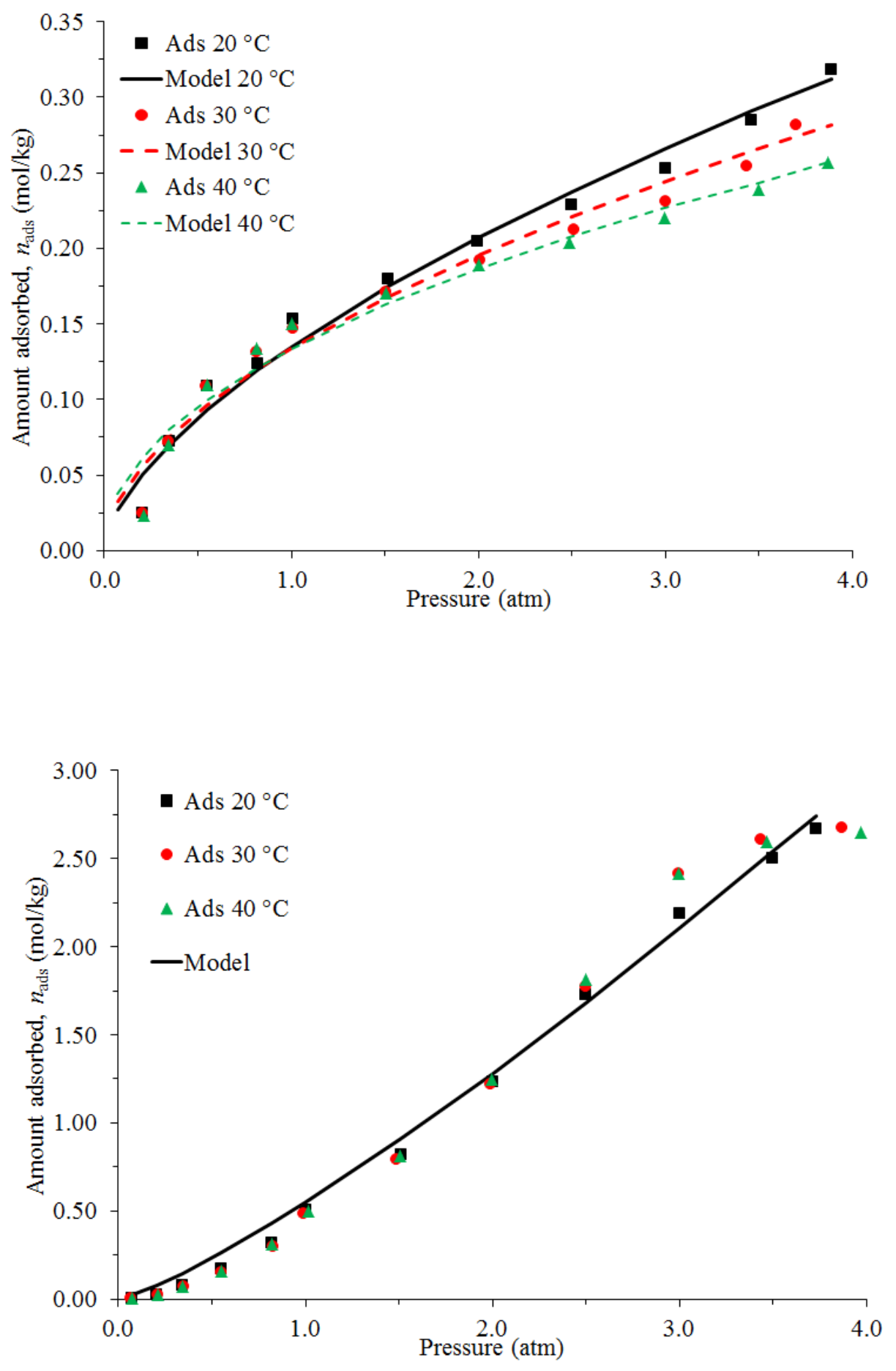


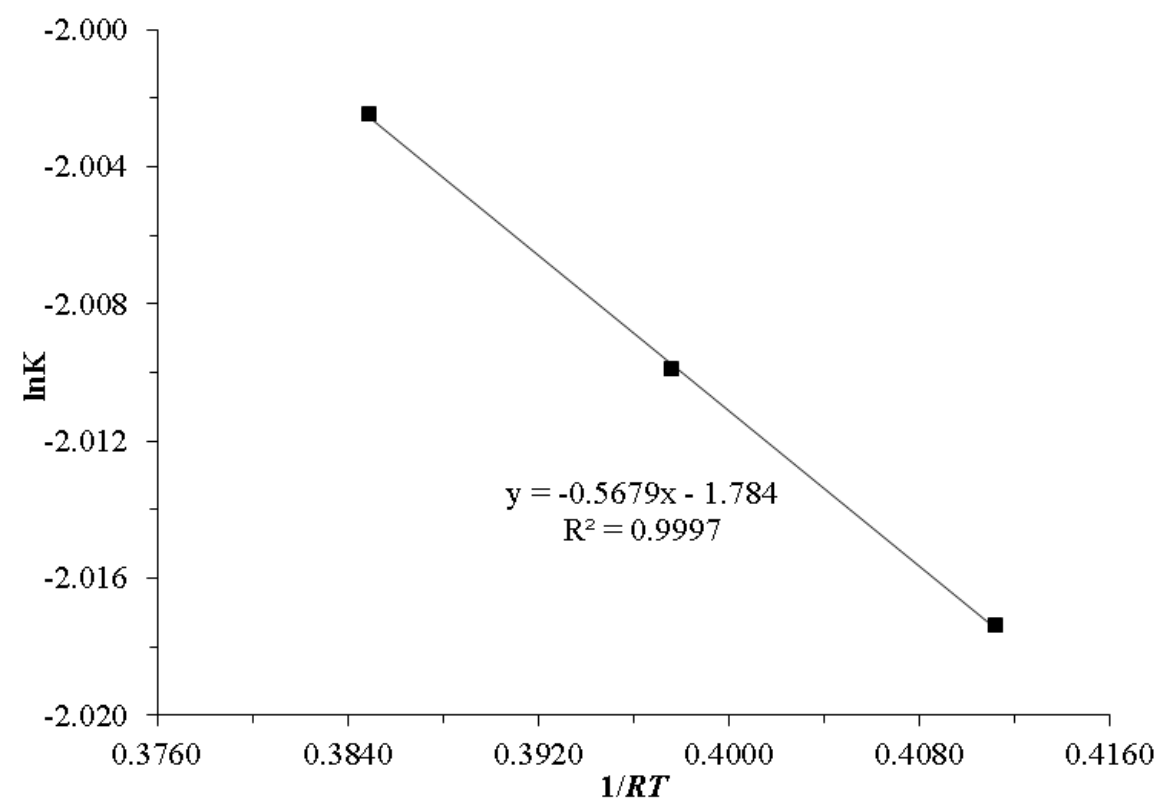



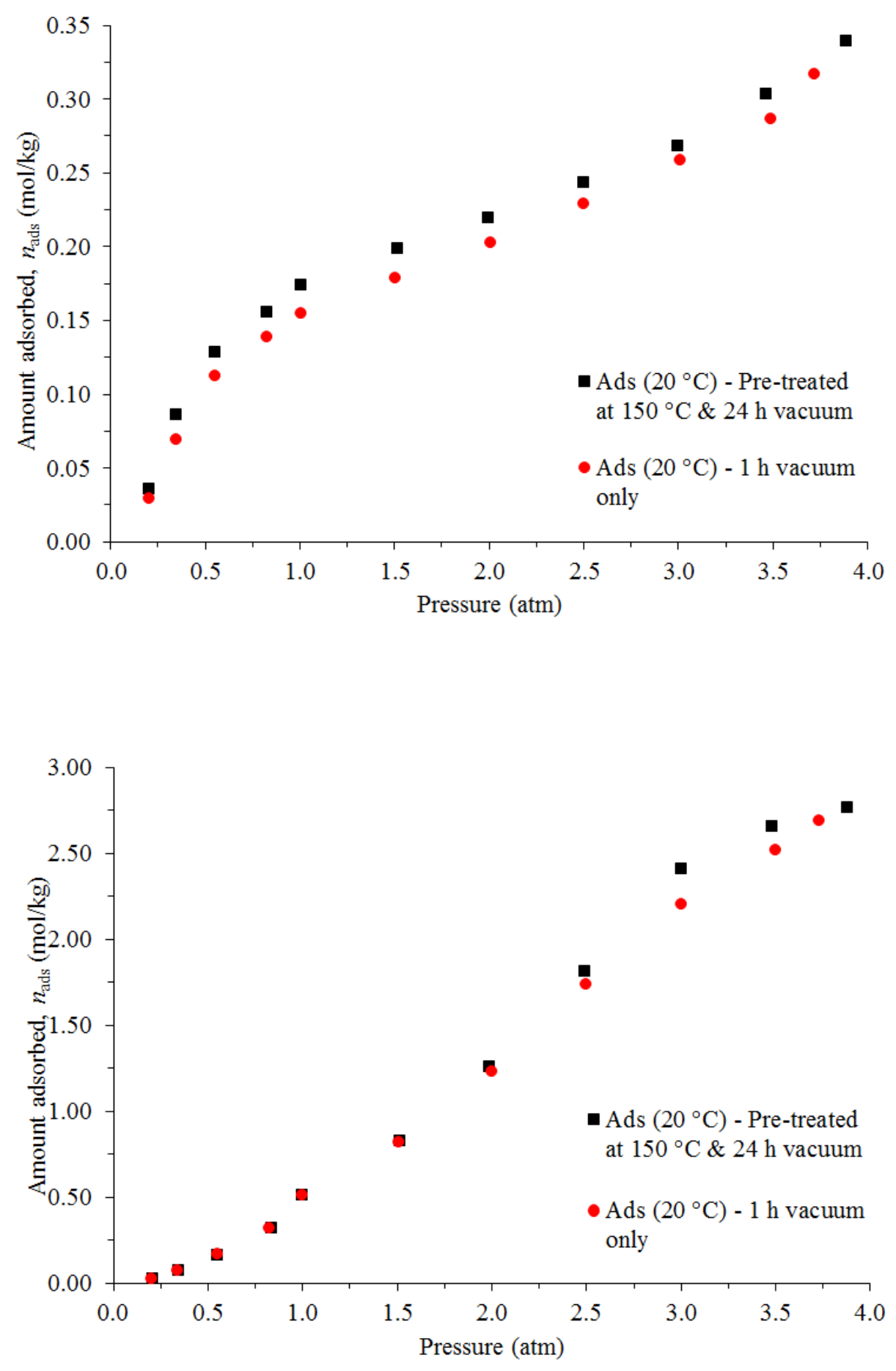


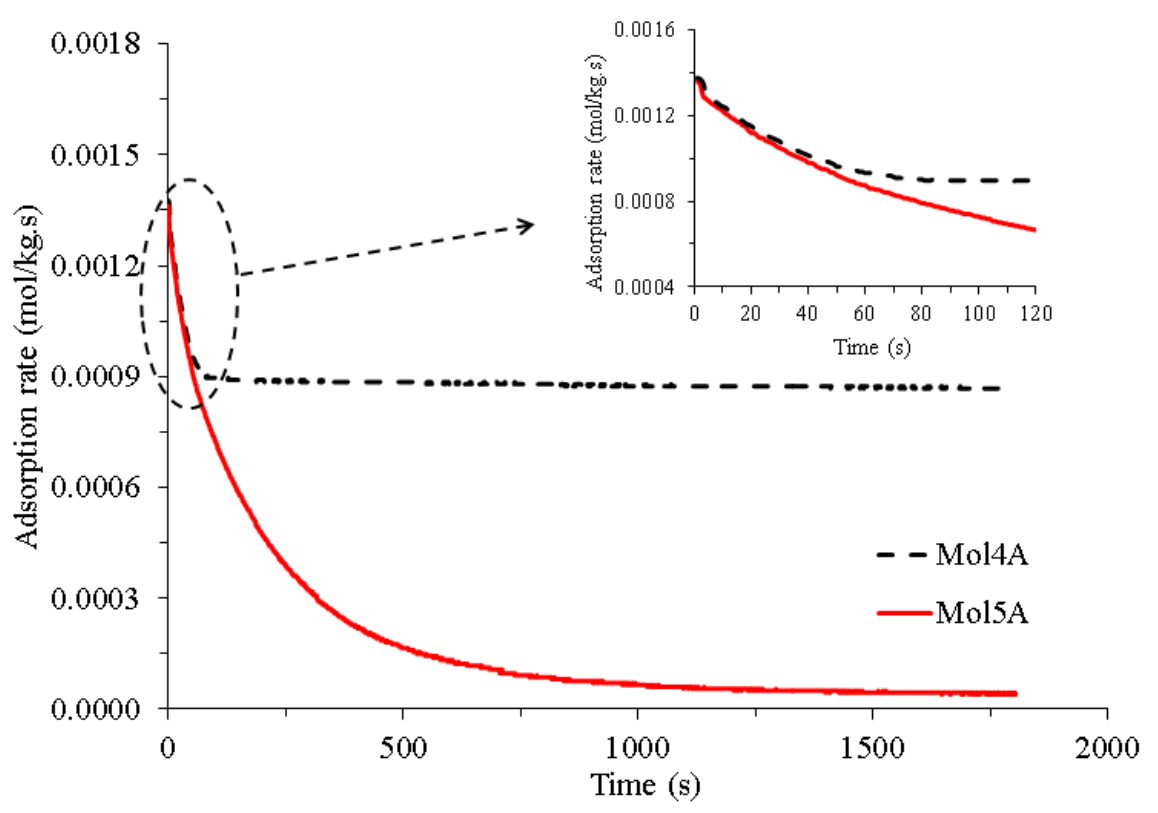



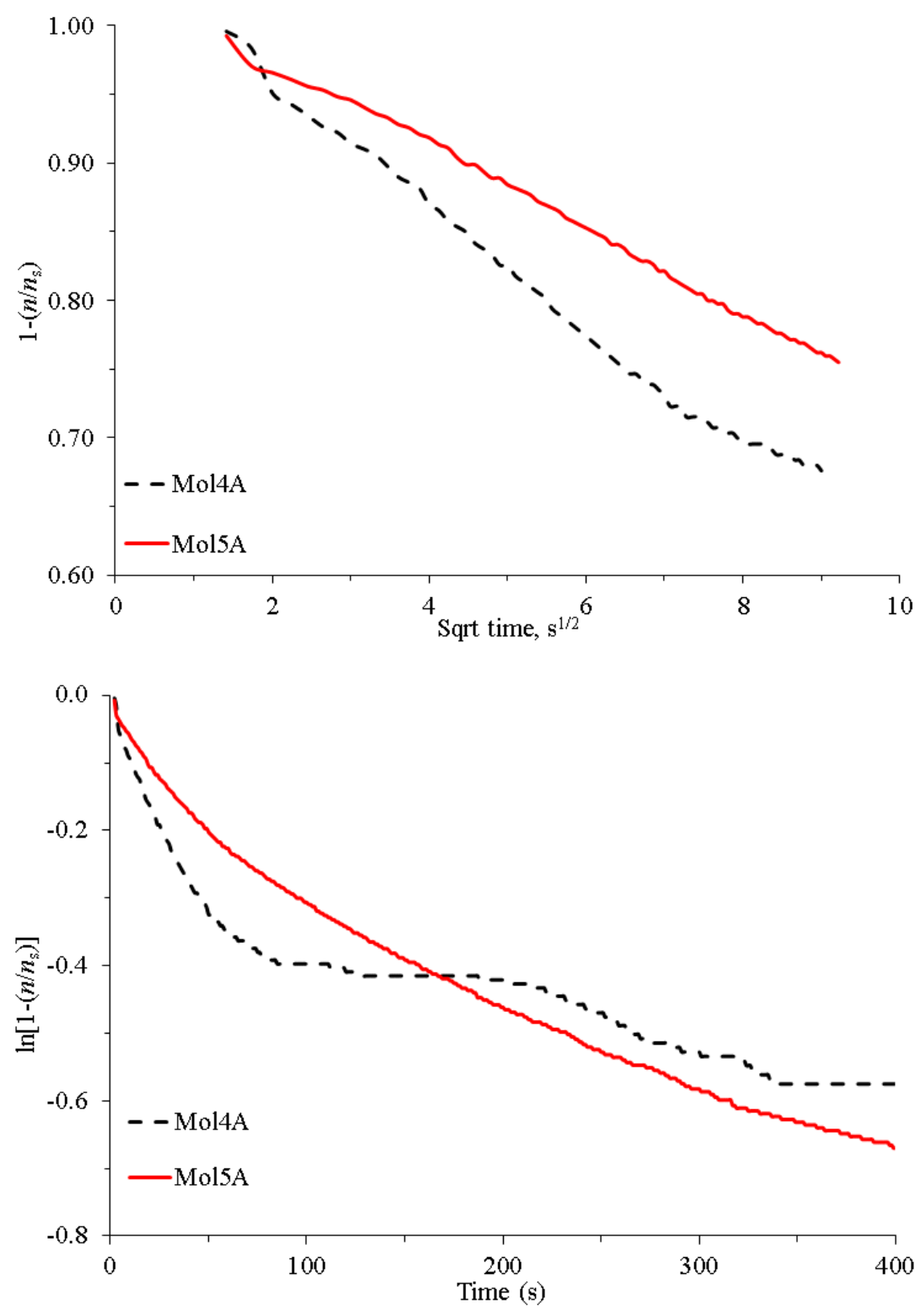

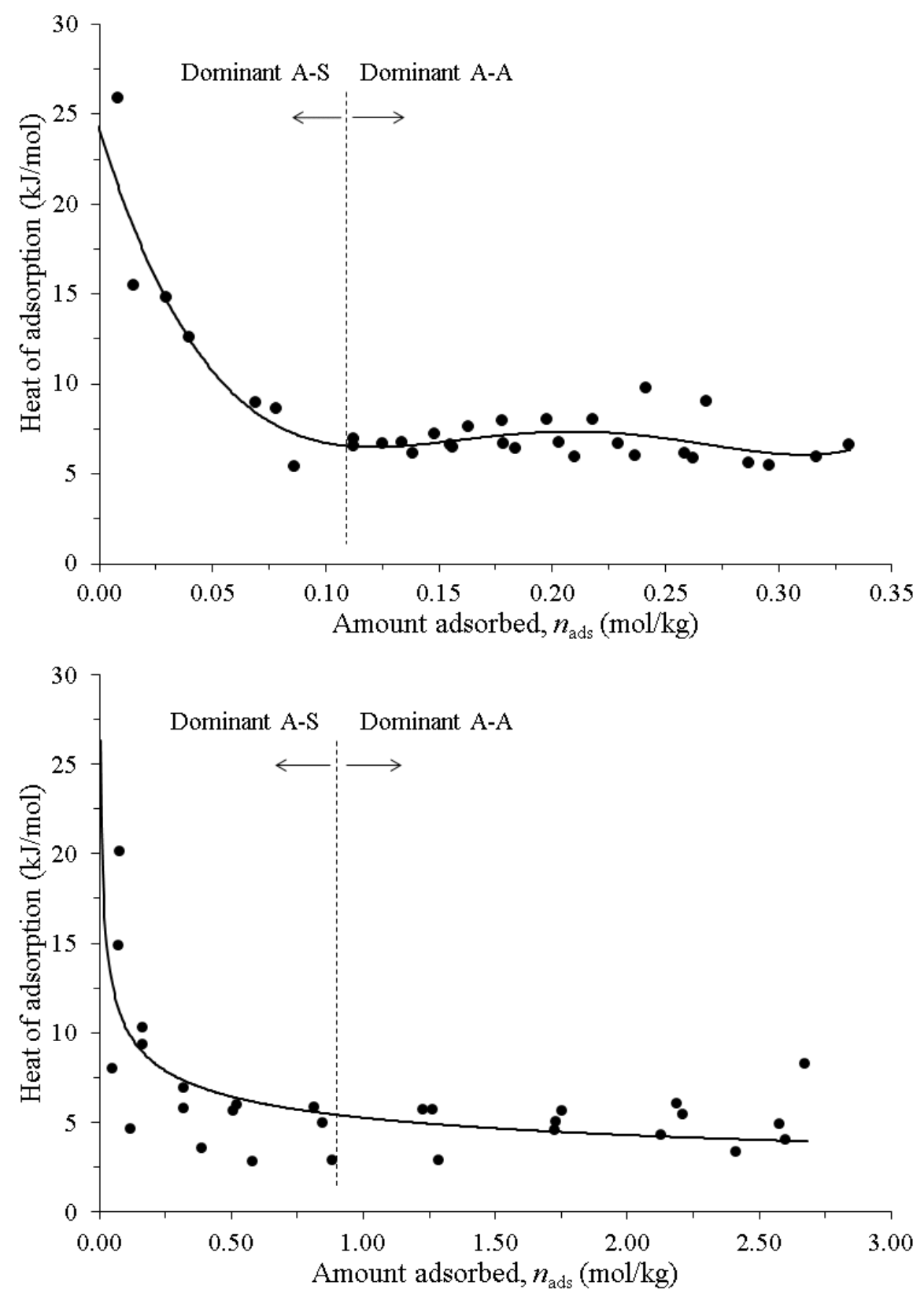
Table 1. Key reported studies on DME adsorption

\begin{tabular}{|c|c|c|c|c|}
\hline $\begin{array}{c}\text { Adsorbent } \\
\text { Type, properties, } \\
\text { method }\end{array}$ & $\begin{array}{c}\text { Conditions } \\
\text { Temperature, pre- } \\
\text { treatment }\end{array}$ & $\begin{array}{l}\text { Amount adsorbed } \\
\qquad \text { Max ads. }\end{array}$ & Comments & Ref. \\
\hline $\begin{array}{l}\text { - Silica gel, surface } \\
\text { area: } 660.0 \mathrm{~m}^{2} \mathrm{~g}^{-1} \\
\text { Particle size: } 75- \\
150 \mu) \\
\text { - Experimental }\end{array}$ & $\begin{array}{l}\text { - Ads. at } 242.2 \mathrm{~K} \\
\text { - Heat-treated gel at } \\
240,500,700 \text { and } \\
900 \mathrm{~K} \text { for } 15 \mathrm{~h}\end{array}$ & $\begin{array}{l}0.288,0.250,0.213 \\
0.095 \mathrm{~g} \mathrm{~g}^{-1}\end{array}$ & $\begin{array}{l}\text { - Type I isotherms; } \\
\text { - Low coverage, } \theta=0.01-0.10 \\
\text { give a high heats of ads. } \sim 20 \text { and } 16 \\
\text { kcal mol }^{-1} \text { ); } \\
\text { - Hydrogen bonding at low } \\
\text { coverage with silanol groups. }\end{array}$ & [9] \\
\hline $\begin{array}{l}\text { - Silica gel, surface } \\
\left.\text { area: } 148.6 \mathrm{~m}^{2} \mathrm{~g}^{-1}\right) \\
\text { - IR spectroscopy }\end{array}$ & $\begin{array}{l}\text { - Ads. At } 293 \mathrm{~K} \\
\text { - Heated and outgassed } \\
\text { at } 873 \mathrm{~K} \text {; - Saturated } \\
\text { with water vapour and } \\
\text { evacuated at } 423 \mathrm{~K} .\end{array}$ & - & $\begin{array}{l}\text { - Hydrogen bonding, interaction } \\
\text { with free isolated; } \\
\text { - Weaker bonding, adsorption on } \\
\text { adjacent silanol groups; } \\
\text { - Both show irreversible adsorption } \\
\text { on due to free isolated silanols. }\end{array}$ & [10] \\
\hline $\begin{array}{l}\text { - Zeolite SAPO-34 } \\
\text { - Surface area: } \\
1247.0 \mathrm{~m}^{2} \mathrm{~g}^{-1} ; \text { Pore } \\
\text { size: } 5.5 \AA) \\
\text { - Volumetric ads. }\end{array}$ & $\begin{array}{l}\text { - Ads. at } 298,333 \text { and } \\
373 \mathrm{~K} \\
\text { - Heated at } 673 \mathrm{~K} \text { and } \\
\text { outgassed for } 5 \mathrm{~h}\end{array}$ & $\begin{array}{l}2.20,1.84,1.25 \\
\mathrm{mmol} \mathrm{g}^{-1}\end{array}$ & $\begin{array}{l}\text { - Adsorbed by more than one DME } \\
\text { molecule per acid site; } \\
\text { - Further adsorption sites at high } \\
\text { pressure to increasing adsorption } \\
\text { with coverage; } \\
\text { - Differential heat } \sim 60-70 \text { initially } \\
\text { then constant } \sim 45 \mathrm{~kJ} \mathrm{~mol}^{-1} \text {; } \\
\text { - Irreversible adsorption quantities } \\
\text { calculated at all temperatures. }\end{array}$ & [11] \\
\hline $\begin{array}{l}\text { - Zeolite H-ZSM-5, } \\
\mathrm{Si} / \mathrm{Al}-12.0 \text { (HZ- } \\
\text { 12), Si/Al- } 27.0 \\
\text { (HZ-27) } \\
\text { - In-situ FTIR }\end{array}$ & 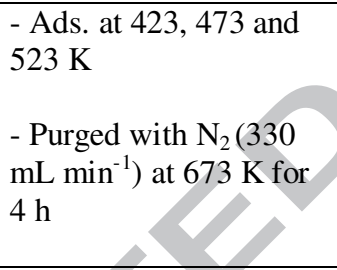 & & $\begin{array}{l}\text { - At } 423 \mathrm{~K} \text { strongly adsorbed on } \\
\text { Brфnsted acid sites; } \\
\text { - At } 473 \mathrm{~K} \text { partial dissociative } \\
\text { adsorption on HZ-12, not with HZ- } \\
27 \text {; } \\
\text { - At } 523 \mathrm{~K} \text { showed dissociative } \\
\text { adsorption. }\end{array}$ & [12] \\
\hline $\begin{array}{l}\text { - Zeolite ZSM-5, } \\
\text { H-ZSM-5 (Si/Al- } \\
\text { 15.0), Na-ZSM-5 } \\
\text { (Si/Al- 26.0) } \\
\text { - In-situ FTIR }\end{array}$ & 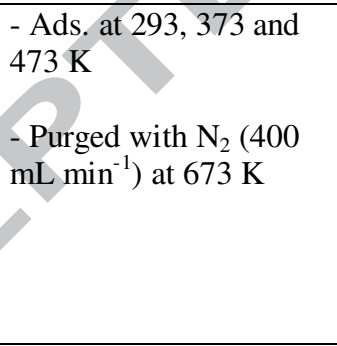 & - & $\begin{array}{l}\text { - At room temp hydrogen bonding, } \\
\text { mainly internally (pores); } \\
\text { - At } 373 \mathrm{~K} \text { only interactions with } \\
\text { internal hydroxyl groups occurs; } \\
\text { - Dissociative adsorption and } \\
\text { chemisorption at higher } \\
\text { temperatures }\end{array}$ & [13] \\
\hline
\end{tabular}


Table 2. Adsorbent physical and chemical properties

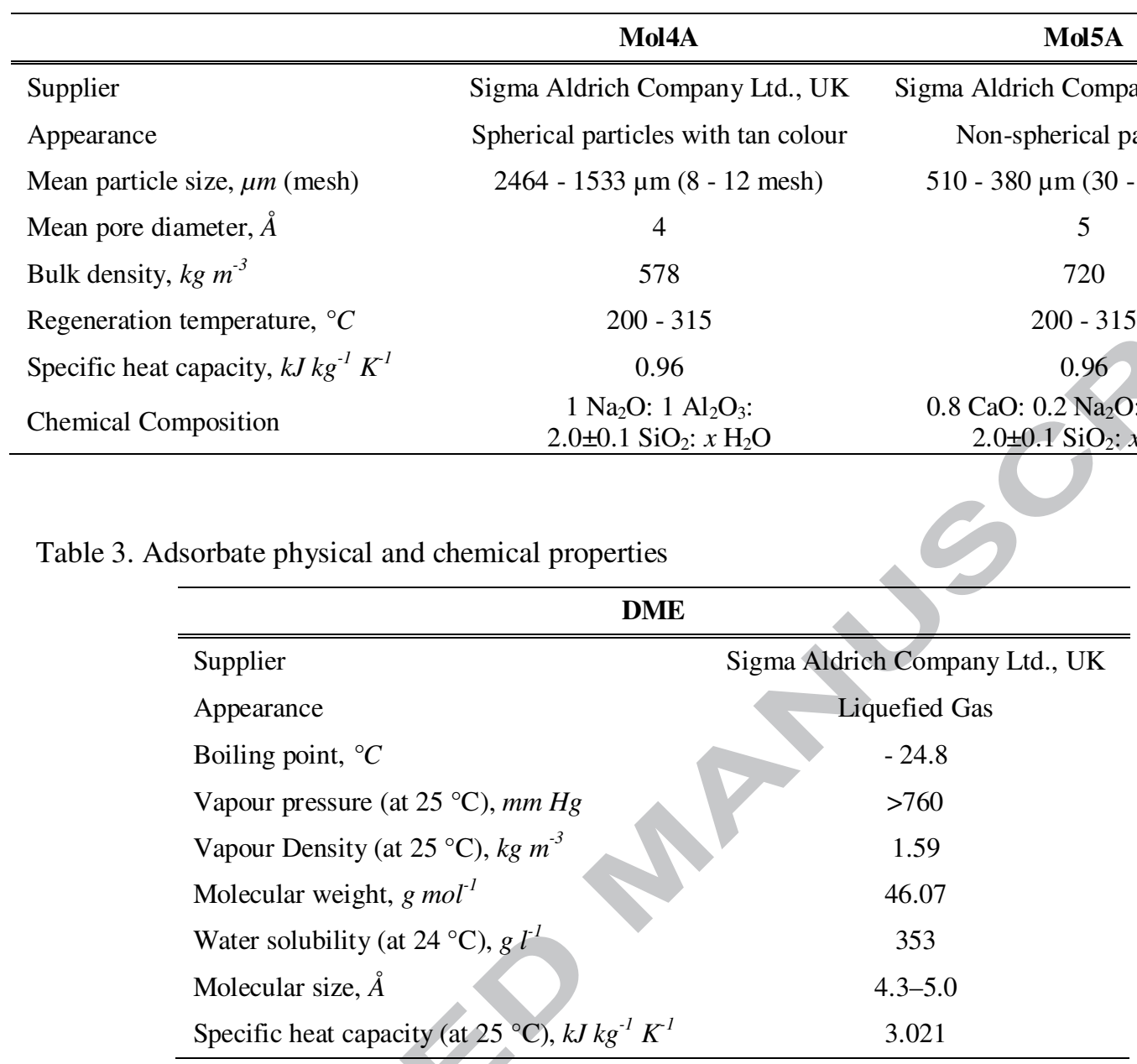

Table 4. BET surface area and pore volume analysis for Mol4A and Mol5A

\begin{tabular}{ccccc}
\hline Adsorbent & $\begin{array}{c}\text { Surface Area } \\
\left(\mathbf{m}^{\mathbf{2}} \mathbf{g}^{-\mathbf{1}}\right)\end{array}$ & $\begin{array}{c}\text { Micropore } \\
\text { Volume }\left(\mathbf{m l ~ g}^{-\mathbf{1}}\right)\end{array}$ & $\begin{array}{c}\text { Micropore Area } \\
\left(\mathbf{m}^{\mathbf{2}} \mathbf{g}^{-\mathbf{1}}\right)\end{array}$ & $\begin{array}{c}\text { Ex. Surface Area } \\
\left(\mathbf{m}^{\mathbf{2}} \mathbf{~ g}^{-\mathbf{1}}\right)\end{array}$ \\
\hline \hline Mol4A & 25.44 & - & - & 25.44 \\
Mol5A & 436.03 & 0.20 & 395.05 & 40.98 \\
\hline
\end{tabular}

Table 5. EDXA analysis of chemical constituents for Mol4A and Mol5A

\begin{tabular}{|c|c|c|c|c|c|c|c|c|c|}
\hline \multirow{2}{*}{ Adsorbent } & C & O & $\mathrm{Na}$ & Si & $\mathbf{K}$ & $\mathbf{C a}$ & Ti & $\mathbf{F e}$ & Al \\
\hline & \multicolumn{9}{|c|}{ Percentage Composition (\%) } \\
\hline Mol4A & Trace & $<67$ & $<10$ & $<6$ & $<7$ & Trace & Trace & $<6$ & $<5$ \\
\hline Mol5A & $<4$ & 43 & $<2$ & $<2$ & $<5$ & 39 & $<3$ & Trace & Trace \\
\hline
\end{tabular}


Table 6. Fitting parameters of the Freundlich empirical model for DME on Mol4A and Mol5A

\begin{tabular}{ccccc|cc}
\hline \multicolumn{5}{c|}{ Mol4A } & \multicolumn{2}{c}{ Mol5A } \\
\hline$k_{1}\left(\mathrm{~atm}^{-1}\right)$ & $k_{2}(-)$ & $T_{\text {ref }}(K)$ & $m(-)$ & $-E_{a}(\mathrm{~kJ} / \mathrm{mol})$ & $K\left(\mathrm{~atm}^{-1}\right)$ & $\alpha$ \\
\hline 0.168 & 1.619 & 293.0 & 3.626 & 0.568 & 0.549 & 0.818 \\
\hline
\end{tabular}

Table 7. Heats of adsorption of DME on Mol4A and Mol5A calculated by the calorimetric and isosteric methods (Clasius-Clapeyron)

\begin{tabular}{ccc|ccc}
\hline \multicolumn{3}{c|}{ Mol4A } & \multicolumn{2}{c}{ Mol5A } \\
\hline $\begin{array}{c}\text { Loading } \\
(\mathrm{mol} / \mathrm{k} / \mathrm{g})\end{array}$ & $\begin{array}{c}\text { Calorimetric method } \\
\left(\mathrm{kJ} \mathrm{mol}^{-1}\right)\end{array}$ & $\begin{array}{c}\text { isosteric method } \\
\left(\mathrm{kJ} \mathrm{mol}^{-1}\right)\end{array}$ & $\begin{array}{c}\text { Loading } \\
(\mathrm{mol} / \mathrm{k} / \mathrm{g})\end{array}$ & $\begin{array}{c}\text { Calorimetric method }_{\left(\mathrm{kJ} \mathrm{mol}^{-1}\right)} \\
\text { isosteric method } \\
\left(\mathrm{kJ} \mathrm{mol}^{-1}\right)\end{array}$ \\
0.105 & 6.62 & 3.95 & 0.9 & 5.09 & 1.00 \\
0.175 & 7.11 & 5.49 & 1.5 & 5.92 & 2.89 \\
0.245 & 7.05 & 6.20 & 2.1 & 6.53 & 1.89 \\
\hline
\end{tabular}




\section{Highlights}

- Dimethyl ether adsorption on molecular sieves Mol4A and Mol5A is experimentally investigated.

- Adsorption capacity of Mol5A is over eight times greater than Mol4A.

- Different adsorption mechanisms dictated by difference in pore size and surface area.

- Freundlich model fitted the adsorption isotherms for both adsorbent.

- Maximum heat of adsorption for both adsorbents is around $25.0 \mathrm{~kJ} \mathrm{~mol}^{-1}$. 